ISSN: 0514-7336

DOI: http://dx.doi.org/10.14201/zephyrus201473149170

\title{
PROCESOS DE APROPIACIÓN Y MEMORIA EN EL SURESTE PENINSULAR DURANTE LA SEGUNDA EDAD DEL HIERRO: MOLINICOS Y LA UMBRÍA DE SALCHITE EN LA CONSTRUCCIÓN DE UN TERRITORIO POLÍTICO
}

\section{Processes of appropriation and memory in the South-east of the Iberian Peninsula during the Second Iron Age: Molinicos and Umbria de Salchite and the shaping of a political territory}

Susana GonzÁlez Reyero*, F.-Javier SÁnchez-Palencia Ramos*, Clara Flores Barrio** e Iván LóPez SALINAS ${ }^{* * *}$

* Instituto de Historia. Centro de Ciencias Humanas y Sociales. CSIC. Cl Albasanz, 26-28. 28037 Madrid. Correo-e: susana.gonzalezreyero@cchs.csic.es; javier.spalencia@cchs.csic.es

** Maison René Ginouvès d'Archéologie et d'Ethnologie. Université Paris X-CNRS. 92023 Paris. Correo-e: clarafloba@gmail.com

***Area de Arqueología. Facultad de Filosofía y Letras II. Campus San Vicente del Raspeig. 03080 Alicante. Correo-e: ivanlopezsalinas@hotmail.es

Recepción: 24/01/2014; Revisión: 6/02/2014; Aceptación: 17/03/2014

BIBLID [0514-7336 (2014) LXXIII, enero-junio; 149-170]

RESUMEN: Este trabajo analiza las formas de apropiación del paisaje por parte de las comunidades de la Segunda Edad del Hierro en la cuenca del río Alhárabe, dentro del territorio más amplio de la cuenca alta del río Segura en el NO murciano. Proponemos la hipótesis de que existió una relación entre los asentamientos del Llano de Moratalla-Calasparra y el santuario de la Umbría de Salchite, ubicado en el contiguo altiplano del Campo de San Juan. Dos tipos de argumentos apoyan esta hipótesis. Por una parte, la constatación de una serie de relaciones entre la cultura material y la iconografía de Molinicos y la Umbría de Salchite. Por otra, el planteamiento de su común vertebración mediante la cuenca del río Alhárabe y mediante una relación de visibilidad, ya que la Umbría de Salchite constituye el horizonte visual de las comunidades que habitaron el área de Molinicos. La memoria de un personaje femenino vinculado al fuego parece ser la base ideológica sobre la que se modeló esta relación entre los dos valles.

Palabras clave: Iberos. Territorio político. Ideología. Memoria. Paisaje simbólico. Ritualización.

ABSTRACT: This paper analyzes the appropriation of landscape developed by the communities of the Iron Age. The area of study is the basin of Alhárabe river within the broader territory of the upper basin of the Segura River in northwestern Murcia. We argue the existence of a relationship between the settlements of Llano de Moratalla-Calasparra and the sanctuary of Umbría de Salchite, located in the adjacent highlands of Campo de San Juan. Two types of arguments support this hypothesis. On one hand, the finding of a series of links between the material culture and iconography of Molinicos and Umbría de Salchite. On the other hand, they are linked by a common backbone, articulated by the 
Alhárabe river basin and also by a relationship of visibility because Umbría de Salchite is the visual horizon of the communities that inhabited the Molinicos area. The memory of a female figure linked to fire appears to be part of the ideological basis on which the relationship between the two valleys was shaped.

Key words: Iberians. Political territory. Ideology. Memory. Symbolic landscape. Ritualization.

\section{La construcción de un territorio. Memoria y cultura material ${ }^{1}$}

La investigación de las últimas décadas sobre la expresión espacial del sistema sociopolítico ibérico viene enfatizando el análisis de los procesos de construcción territorial y la definición de las variadas formas de apropiación del paisaje -ver, entre otros, Ruiz et al., 2001; Ruiz y Molinos, 2002; Grau, 2002, 2007, 2010; Burillo, 2007-. Nuestro propósito es contribuir a esta investigación mediante el análisis de un caso del sureste de la Península Ibérica, concretamente en la cuenca del río Alhárabe en el noroeste murciano (Fig. 1).

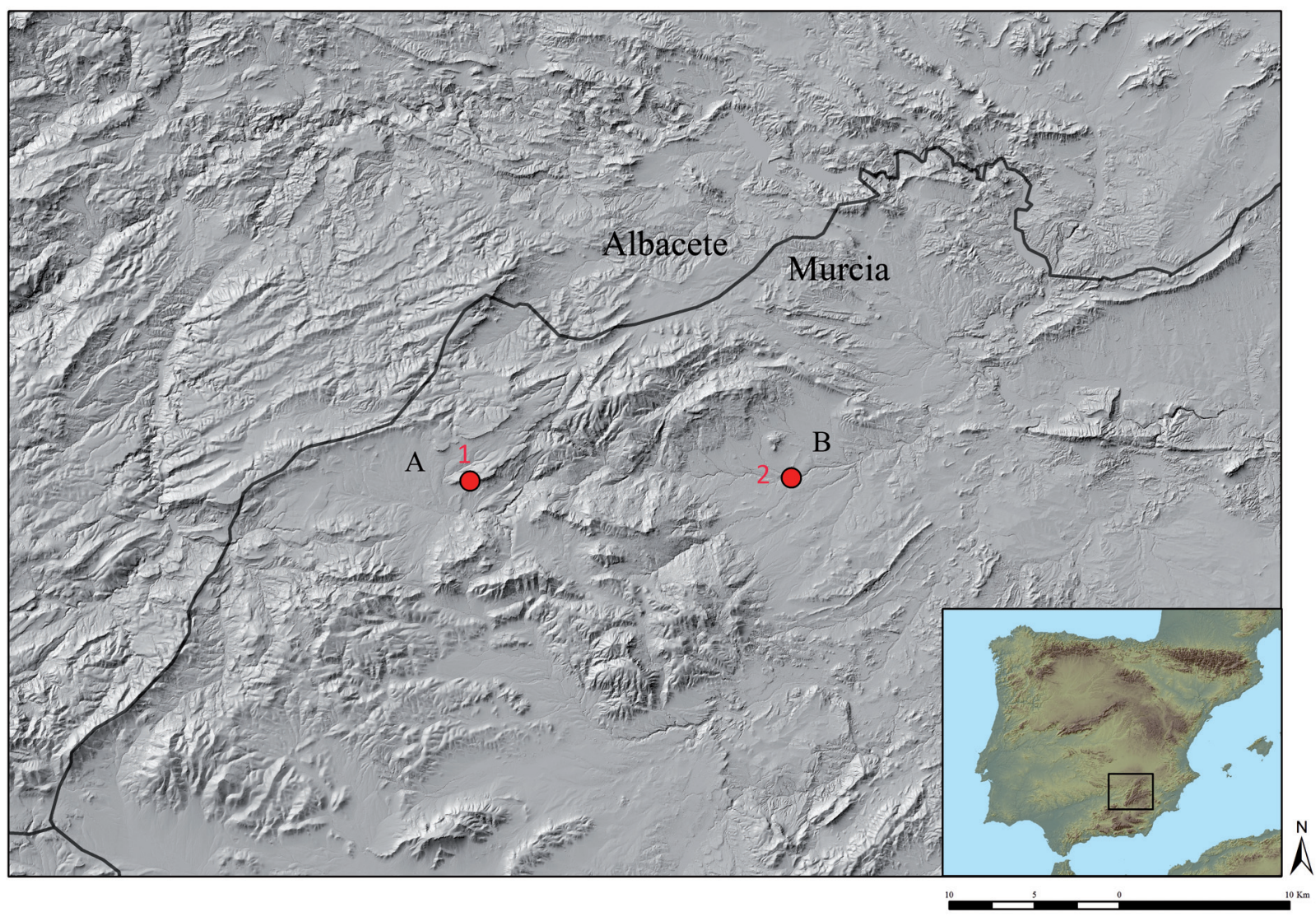

FIG. 1. Ubicación de la zona de estudio en el SE peninsular: A) Campo de San Juan y B) Llano de Moratalla-Calasparra; 1) Umbría de Salchite y 2) Molinicos (@ J. L. Pecharromán, LABTEL, CCHS-CSIC).

${ }^{1}$ Este trabajo ha sido realizado dentro de los proyectos "Paisajes simbólicos y espacios productivos en los procesos de jerarquización social del sureste peninsular durante la Edad del Hierro" (HAR2012-35208) del Plan Nacional de I + D del MINECO y "Estudio del poblamiento de la edad del Hierro en la cuenca alta del río Segura: el valle de Jutia y la ocupación ibera de las áreas de sierra”, del Instituto de Estudios Albacetenses. Asimismo se incluye en las actividades de la Unidad Asociada del CSIC 'Arqueología del Paisaje: lecturas territoriales y simbólicas'. Deseamos agradecer las aportaciones y comentarios de I. Grau y de J. García Cardiel, así como el trabajo de J. L. Pecharromán del Laboratorio de Arqueología del Paisaje y Teledetección (LabTel) del IH, CCHS-CSIC. Igualmente, los revisores anónimos han realizado comentarios relevantes que hemos intentado incorporar al trabajo. 
Este trabajo se enmarca a su vez en nuestro actual estudio de un territorio más amplio, definido por la cuenca alta del río Segura.

Atenderemos a la larga diacronía y a los procesos de memoria como perspectiva fundamental para aproximarnos a las formas en que se construye el territorio y se definen socialmente los límites territoriales. Plantearemos cómo, si no es mediante esta larga diacronía, es muy difícil poder analizar las implicaciones sociales y territoriales de imágenes tan debatidas como las de La Nariz en la Umbría de Salchite. Sin la larga duración, defenderemos, no es posible comprender cómo se construye el territorio, ni las eventuales materialidades y cambios en dicha construcción.

Esta perspectiva de la larga duración está muy lejos de querer defender clichés fijos o contenidos inalterados a lo largo del tiempo. Por el contrario, enfatizaremos las transformaciones que experimentan las comunidades implicadas. Es preciso para ello especificar brevemente nuestra aproximación a los procesos de memoria, como concepto clave que vertebra este artículo.

La memoria, o más bien el estudio de las huellas materiales de prácticas mnemónicas, está emergiendo como un campo central en la investigación arqueológica actual, a cuya bibliografía reciente remitimos (Rowlands, 1993; Alcock, 2002; Bradley, 2002; Van Dyke y Alcock, 2003; Jones, 2007; Boric, 2010; Lillios y Tsamis, 2010; Jones et al., 2012). Frecuentemente la arqueología ha considerado que la cultura material es capaz no sólo de contener en sí información, sino también de transmitirla. Sería una especie de almacén externo de información, en ocasiones simbólica. Esta concepción aparece, más o menos implícita, en buena parte de las aproximaciones arqueológicas a la memoria.

Esa noción del contenedor externo donde se almacena información conlleva varios problemas. Uno, que subrayamos como central, es que la memoria implica siempre un grado de interpretación (Fentress y Wickham, 1992: 31). Por eso, nuestra aproximación está más de acuerdo con las perspectivas que enfatizan el carácter de los objetos o los paisajes como huellas físicas de hechos pasados que requieren necesariamente de posteriores procesos de lectura para formar parte de nuevos procesos sociales (Jones, 2007). Desde esta perspectiva no es posible transmitir significados fijados ya desde el momento de la fabricación de cualquier objeto o estructura. Su acción dentro de las relaciones sociales demanda siempre una relectura activa (Thomas, 1998: 153). Por ello, esta "naciente arqueología de la memoria" (Insoll, 2011: 3) enfatiza el hecho de que recordar es, fundamentalmente, una acción. Subrayamos, por tanto, el acto de leer como una práctica creativa, situacional y fundamentalmente activa. Además, la memoria tampoco es algo dependiente únicamente de la mente, sino que es preciso introducir la corporalidad de los gestos, el movimiento y la repetición como elementos fundamentales del aprendizaje, del habitus y de la reproducción social de la comunidad (Bourdieu, 1972). Dentro de esta perspectiva de la teoría de la práctica, nos acercaremos a los rituales en cuanto prácticas dotadas de materialidad (LópezBertrán, 2011: 87).

Desde esta perspectiva es crucial tener en cuenta la flexibilidad de los actos mediante los que se crean recuerdos y, por tanto, el margen que permiten para la innovación, la manipulación o el cambio. Es decir, más allá de una concepción pasiva de la cultura material o del paisaje, como un depósito o reserva de ideas con significados fijos transmisibles en el tiempo, nuestra propuesta es atender a las amplias posibilidades que introducen la propia materialidad de los objetos, su naturaleza mnemónica y la corporalidad de las acciones necesarias para el recuerdo y la memoria, así como el margen que esto proporciona para alterar los procesos de reproducción social.

\section{El espacio sagrado: La Nariz y la Umbría de Salchite (Moratalla, Murcia)}

Desde que P. Lillo descubriese para la investigación los hallazgos de La Nariz, en la zona de la Umbría de Salchite de Moratalla (Murcia), varios estudios se han ocupado de hipotetizar sobre sus restos materiales, a los que remitimos para las diferentes lecturas elaboradas hasta ahora (Lillo, 1981: 39; 1983: 769-787; González-Alcalde y Chapa, 1993: 169-174; Olmos, 1996: 275, fig. 3; 1999, n.o 70: 2; Almagro-Gorbea, 1997: 109-112; 


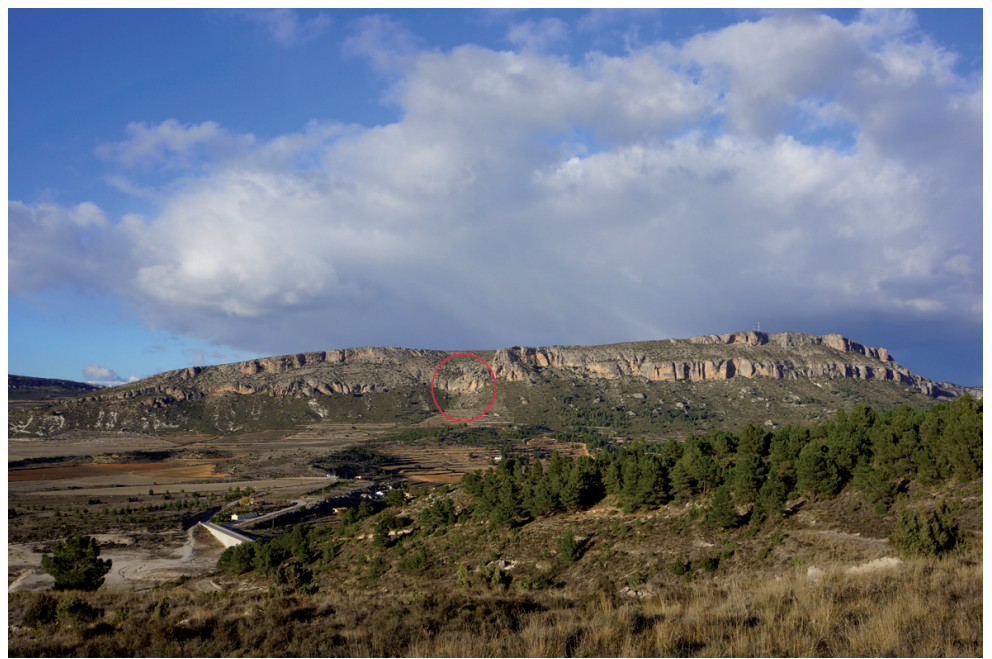

Fig. 2. Vista general del macizo de la Umbría de Salchite (Moratalla, Murcia) con indicación del área del santuario antiguo.

del agua, esta zona del imponente macizo, contribuyendo posiblemente al significado cultural otorgado al lugar. Esta idea se afianza si tenemos en cuenta las piletas internas excavadas en las dos cuevas, que apuntan a que el agua recogida en ellas tuvo su papel en las prácticas del santuario.

La discusión arqueológica se ha centrado, y focalizado casi exclusivamente, en la iconografía llamativa de un fragmento de urna, pasando más desapercibido el resto de la cultura material asociada, a pesar de su publicación por Lillo $(1981,1983)$ y González-Alcalde (2005). Por nuestra parte, nos centraremos brevemente en este contexto material más amplio, compuesto por formas de campaniense A (Lamboglia 5, 27, 29 y 31), un

González Alcalde, 2005, 2006; Moneo, 2003; Brotons y Ramallo, 2010: 139; Ocharán, 2013)².

El contexto de los hallazgos son dos cuevas, denominadas popularmente por su morfología La Nariz, y su entorno inmediato; todo ello es parte de la fachada meridional del macizo llamado Umbría de Salchite o Calar de la cueva de la Capilla (Fig. 2), ubicado en el extremo NO del término de Moratalla en la Comunidad Autónoma de Murcia.

Las connotaciones y prácticas sociales atribuidas a determinados lugares naturales han sido objeto de una amplia investigación, denominada "arqueología de los lugares naturales" a partir de la conocida obra de Bradley (2000). En nuestro caso, destacamos cómo la amplia fachada sur de la Umbría de Salchite adopta una morfología peculiar en la zona donde se ubican las dos cuevas de La Nariz, un entrante que facilita el discurrir de una corriente de agua y que permite que sea una zona a la umbría la mayor parte del día (Fig. 3). Estos rasgos morfológicos son fácilmente diferenciables en el paisaje abierto del Campo de San Juan y habrían singularizado, junto al discurrir

2 También González-Alcalde, J. (2002): Las Cuevas Santuario y su incidencia en el contexto social del Mundo ibérico. Tesis doctoral presentada en 2002 en la UCM ([consultada: 18-10-2013] <http://eprints.ucm.es/22157/>). fragmento de ánfora Dressel I y, sobre todo, pequeños vasos globulares de borde exvasado, de pasta gris o pintados (Fig. 3). En cuanto a los metales destaca un as republicano, un clavo de cabeza cónica, una hoja de flecha, un pequeño umbo, anillos de cobre, un regatón de pilum y un diente con un orificio transversal perteneciente a un carnívoro, ya sea un lobo (Lillo, 1983: 39 y 769-781; González-Alcalde y Chapa, 1993: 169174) o un lince (Ocharán, 2013: 17).

Algunos elementos de esta cultura material se han utilizado para subrayar la posibilidad de que ciertas prácticas se hubiesen llevado a cabo en el santuario. Así, la presencia de anillos y aros se ha relacionado con la iniciación y la posible ofrenda ritual de pelo en la Umbría (González-Alcalde, 2011: 144) al igual que en otros lugares del Mediterráneo antiguo (Cartledge, 1979: 91) y que en los santuarios iberos de la Alta Andalucía (Rueda, 2011). Igualmente, los hallazgos de formas cerámicas abiertas han servido para apuntar posibles prácticas de libación (González-Alcalde, 2011: 141) durante la frecuentación del santuario.

Por nuestra parte, vamos a detenernos en la presencia de grandes vasos pintados, como la urna ovoide más conocida del santuario. Respecto a estos vasos es interesante constatar el hallazgo de lañas de plomo (Lillo, 1983; Ocharán, 2013), que subrayamos en cuanto indicio de reparaciones 


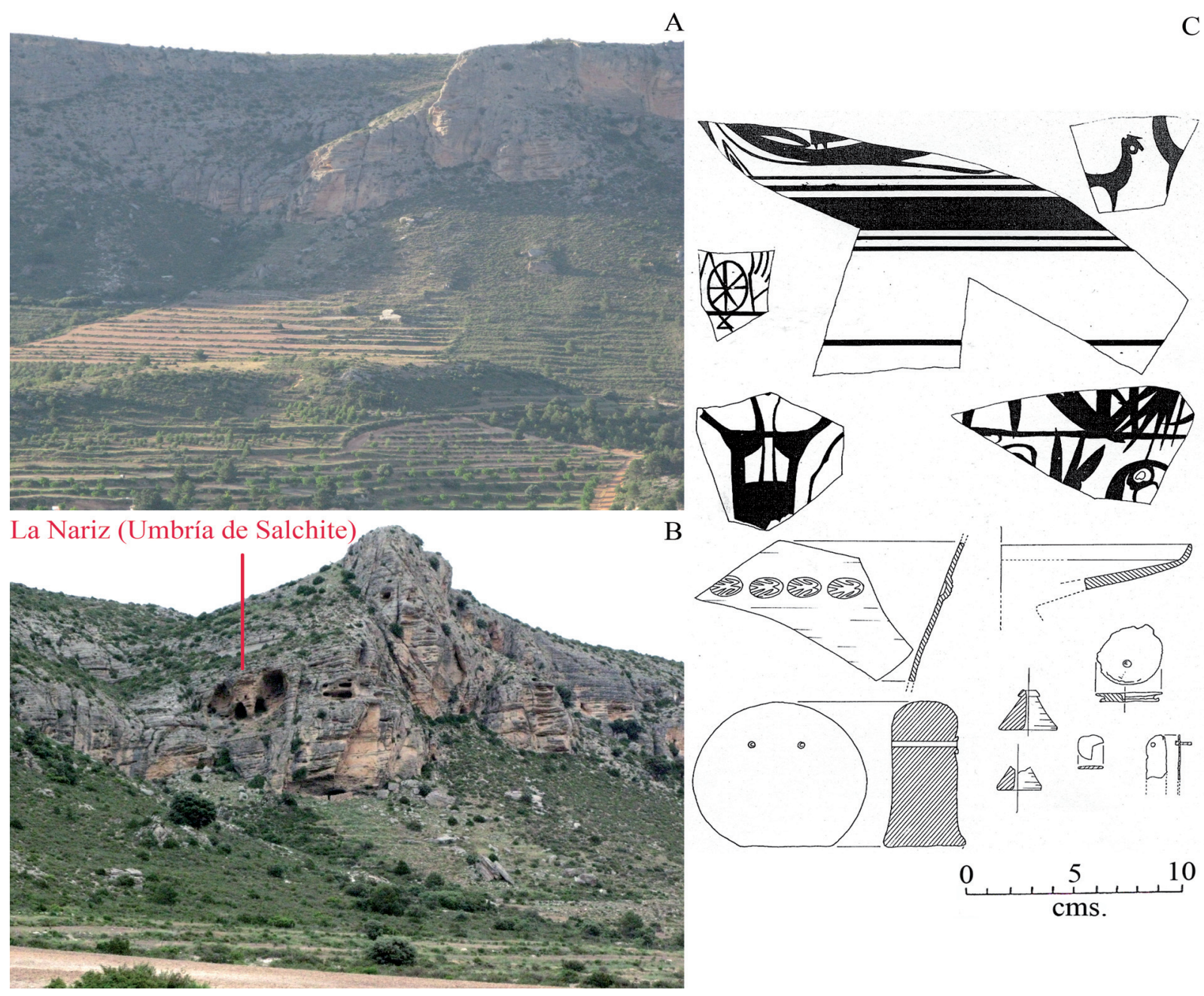

FIG. 3. Zona de La Nariz en la Umbría de Salchite: A) y B) perspectivas de la ubicación del santuario y C) materiales recuperados (Lillo, 1983: fig. 6).

que podrían indicar el aprecio y la voluntad de que esos vasos continuaran utilizándose en el marco del santuario, quizás por el mensaje de su decoración figurada y por su papel vehicular en el culto. Por ello nos referiremos a ellos como posibles vasos de memoria, retenidos y reparados por la comunidad. Todo ello, y de acuerdo con el registro arqueológico conocido hasta ahora, permite fechar la frecuentación del santuario, o al menos la mayor visibilidad de sus prácticas, entre los s. II y I a. C.

Este es el contexto de la conocida urna con decoración figurada que ha focalizado el debate arqueológico sobre la Umbría (Fig. 4). Sin pretender aquí abordar un análisis iconográfico exhaustivo, que no constituye nuestro objetivo en este trabajo, vamos a detenernos en ciertos aspectos al tiempo que enfatizamos la necesidad de integrar su análisis en el resto del registro arqueológico del santuario.

La imagen más conocida de la Umbría de Salchite es un fragmento cerámico con decoración figurada perteneciente a una urna ovoide. El espacio de la representación se fragmentó o metopizó en diferentes cuadrantes, como ocurre también en vasos como el de Oliva (Olmos, 1999: n. ${ }^{\circ} 80.1$; Aranegui, 2004). Hay por tanto una separación buscada, una fragmentación de la imagen mediante líneas que puede estar aludiendo a tiempos o espacios distintos, pero que también marcan el 


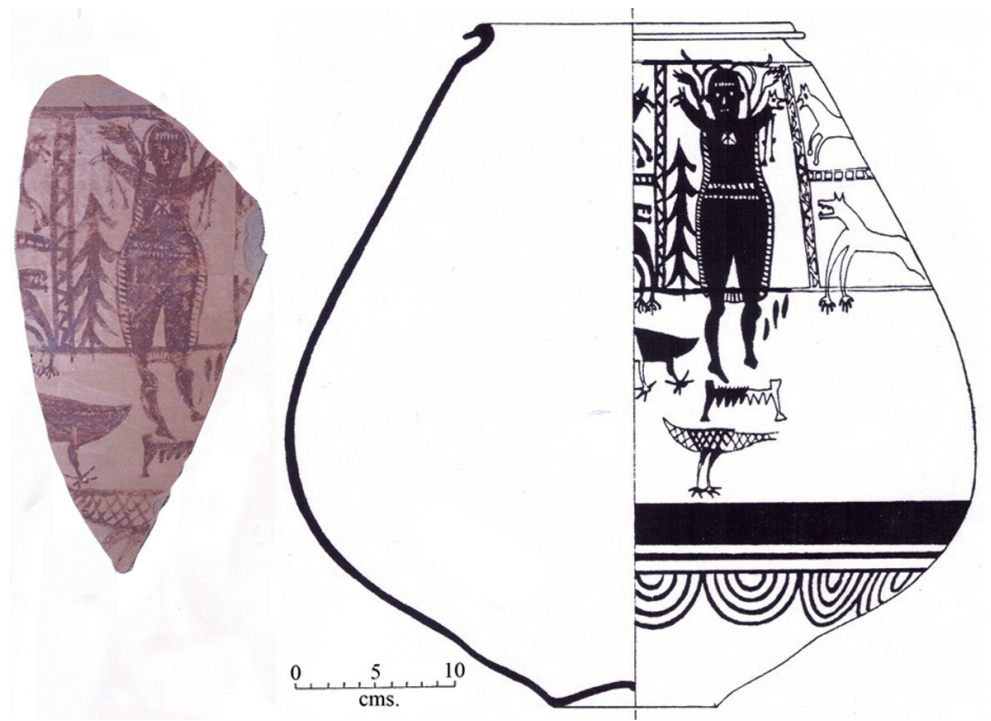

FIG. 4. Fragmento de urna con decoración figurada procedente de la Umbria de Salchite y propuesta de reconstrucción.

humano se funde y representa con otra naturaleza, la de los carnívoros, a quienes de esta forma se vincula. Se representa, por tanto, esta vinculación entre ambas naturalezas, el instante preciso en que se hace clara la relación del personaje antropomorfo con los animales. Otros atributos son menos claros, como los elementos lineales sobre su cabeza, ya sean brotes vegetales, un peinado o alas (Olmos, 1999: n. ${ }^{\circ}$ 70. 2), aunque nos parece relevante señalar el esfuerzo por representar una serie de elementos alrededor de la cabeza.

Además del cinturón y la diadema sólo se indica un elemento más, ubicado en la parte central del cuerpo y que ha sido interpretado como la representación esquematizada de una roseta (Olmos, 1999) o como un posible amuleto hexagonal similar a

gran tamaño del personaje femenino representado, que desborda el espacio marcado por las líneas y dobla, por ejemplo, el tamaño de los carnívoros.

Esta representación femenina ha focalizado hasta ahora un interés centrado en buena parte en una discusión en torno a su naturaleza divina o humana. Elegir la tinta plana como técnica condicionó posiblemente los escasos elementos representados, siendo por ello tan elocuentes los elementos presentes como los ausentes. Es una figura que aparece de frente y con los brazos en alto. Viste un largo velo que le cae por la espalda desde la cabeza. Dentro del esquematismo general, se representa una diadema que ciñe su frente y un cinturón, elementos ambos relacionados recurrentemente con una representación cercana al ámbito sagrado (Ruiz y Molinos, 2007). Subrayamos cómo los brazos parecen terminar en protomoi de carnívoros, algo relacionado con su naturaleza híbrida para quienes han hipotetizado su naturaleza divina o quizás con la epifanía de la diosa (Olmos, 1996: 275, fig. 3); quienes apuntan a su naturaleza humana lo interpretan como posibles pieles que identificarían a quien media en prácticas de iniciación social o al animal mediante el cual se accede a esos ámbitos (González-Alcalde, 2005). En cualquier caso, lo que nos interesa destacar aquí es que de esta manera el personaje los representados en una cerámica de La Luz (Brotons y Ramallo, 2010: 140). Por nuestra parte, señalamos su semejanza con un motivo que aparece en la plástica vascular coetánea, en que dos triángulos enfrentados forman el marco en el que suele "brotar" o "surgir" un elemento vegetal o una figura antropomorfa, como en una cerámica de la villa de Hellín (Sanz, 1997: 43, fig. 13, n. ${ }^{\circ}$ $128,286)$. Sería, en este caso, la representación esquematizada de un ánodos y portaría una idea de generación y fertilidad, coherente con prácticas rituales relacionadas con un culto ctónico.

En el momento elegido para la representación la figura femenina no está sola y nos interesa subrayar qué seres se escogen para acompañarla. A su alrededor aparecen dos carnívoros, un elemento posiblemente vegetal -ya sea árbol o espiga; ver en este sentido Brotons y Ramallo (2010: 138) $y$, en el plano inferior, varias aves y un brasero. En primer lugar, es preciso subrayar esta vinculación de aves y carnívoros con el personaje femenino y cómo se trata de una asociación recurrente en el mundo ibérico. Un ejemplo de ello es el mosaico de Cerro Gil en Iniesta, Cuenca (González Reyero, 2012), que guarda interesantes paralelismos con la Umbría en cuanto al también carácter frontal de la diosa alada, que aparece igualmente 
con diadema y rodeada de carnívoros y aves que definen cualitativa y espacialmente la representación. Sin embargo, y mientras que en Cerro Gil la diosa permanece sentada y con sus alas explayadas, en Salchite aparece de pie, especificando una acción que se desarrolla alrededor de un elemento, el brasero, que incluye unos motivos que sugieren llamas (González-Alcalde, 1993: 67-78). En la Umbría, la presencia del brasero y el fuego nos remite a una actividad y a un tiempo específico, que son los elegidos para la representación. Por su parte, el elemento vegetal pudo identificar el espacio exterior de la acción, quizás la eschatiá, o bien recordar una columna sagrada como elemento vinculado al ámbito sagrado (García Cardiel, 2013).

Si nos alejamos de la cultura material y nos centramos en el espacio físico que ocupa la Umbría, nos encontramos con que el santuario se ha descrito frecuentemente como un lugar remoto, permaneciendo así desconectado del poblamiento de la zona. En nuestra opinión esta idea aísla a la Umbría de los procesos sociales del territorio. Por ello, nuestro objetivo es precisamente integrar su estudio dentro de procesos sociales concretos y dentro de aproximaciones arqueológicas que abogan por una comprensión más matizada de la vida cultural de las cuevas, superando la clasificación funcional tradicional y reconociéndolas como entornos que, por sus características precisas y multisensoriales, ofrecen a diferentes comunidades oportunidades para expresar y experimentar una amplia gama de ideas acerca de las identidades humanas y sobrenaturales. Son, por ejemplo, lugares susceptibles de ser percibidos como liminales. Esta perspectiva conlleva también intentar integrar su estudio dentro de un modelo de poblamiento determinado, insistiendo en las posibles relaciones contextuales con otras formas de monumentos o asentamientos (Skeates et al., 2013: 97).

En la Umbría de Salchite es preciso comenzar con las evidencias de una frecuentación o asentamiento en las inmediaciones del santuario durante el Bronce pleno, concretamente en la cima del Calar de la Cueva de la Capilla (Medina, 2013), que nos permite argumentar la antigüedad de la frecuentación de este lugar y cómo, por su morfología y materialidad, esta estructura antigua podría haber sido percibida como un hito en el paisaje, ya que es claramente perceptible en la silueta del macizo de la Umbría de Salchite (Fig. 2). Otro indicio de la frecuentación antigua del lugar es la cercanía de las pinturas rupestres y del asentamiento del Bronce de la Risca (López, 1991).

Podemos decir, por tanto, que la frecuentación del santuario encapsuló e incorporó una memoria del lugar más antigua (Jones, 2007: 15). Pero, además de esta biografía previa del lugar, es preciso insistir en la presencia del agua, tanto en el farallón de la Umbría de Salchite inmediato a La Nariz como dentro de las propias cavidades de La Nariz. La relación cueva-corriente de agua influyó posiblemente en la elección del lugar, algo señalado en otros santuarios ibéricos y recurrente tanto en la Prehistoria europea (Scarre, 2011: 10) como en otros ámbitos mediterráneos (López-Bertrán, 2011). La presencia en la Umbría de unas cavidades o piletas que potencialmente habrían retenido el agua nos indica que el agua debió ser un elemento participante en las prácticas llevadas a cabo en el santuario. En este sentido, el agua y los ciclos hidrológicos son elementos recurrentemente utilizados por diferentes cosmologías para crear construcciones sobre las relaciones entre las esferas humana y sobrenatural (Oestigaard, 2011: 47).

Algunas cualidades más diferenciaban a la Umbría en ese paisaje visitado con anterioridad. Como en otras cuevas, podemos destacar la presencia de una arquitectura natural multisensorial, con características específicas respecto a la temperatura, humedad, corrientes de agua o sonoridad distorsionada, que invitaban y desafiaban a la exploración humana y a su potencial apropiación. Estas características naturales fueron embebidas de diferentes formas, como se ha estudiado en otros ámbitos, dentro de contextos sociopolíticos complejos. De esta forma, las cavidades pudieron establecerse como lugares sagrados, asociados con seres sobrenaturales y con prácticas rituales repetitivas, acciones que conllevaron la instalación, consumo, deposición y destrucción de una cultura material en ocasiones de valor. Como nodos de un paisaje connotado, las cuevas ofrecieron así oportunidades para que determinados grupos sociales expresasen y experimentasen toda una serie de ideas sobre las fronteras entre lo social y lo sobrenatural. De esta forma, las prácticas desarrolladas en estos lugares contribuyeron a definir la identidad social a cada momento (Skeates et al., 2013: 122). 
Los párrafos precedentes han intentado exponer la necesidad de integrar a la Umbría dentro de los procesos sociopolíticos locales. Antes que un carácter remoto, subrayamos la teatralidad del espacio de la Umbría por un conjunto de cualidades precisas, diferenciadoras y fácilmente distinguibles en la distancia. La propia ubicación del santuario le permite controlar visualmente la totalidad del Campo de San Juan, sobre el que se sobreeleva unos $200 \mathrm{~m}$. También es visible desde un amplio territorio, se ubica junto a un hito construido anteriormente en el paisaje y junto a una corriente de agua que corre por la ladera adyacente. Además, es morfológicamente singular por la sombra mantenida en la zona del santuario respecto al resto del imponente macizo. Así pues, concebimos el santuario como un hito de connotaciones precisas cerca de dos vías de paso tradicionales, tanto al $\mathrm{N}$-cordel a Hellín- como al s -cordel a Moratalla-. Esto nos aleja de la visión del santuario como un hito aislado y nos permite defender que su análisis debe partir ineludiblemente de su integración en el poblamiento del territorio, uno de los aspectos desatendidos respecto a la Umbría de Salchite. A ello nos acercaremos a continuación, no antes sin tener en cuenta el carácter provisional de nuestra hipótesis por el parcial conocimiento del poblamiento ibérico de la zona.

\section{Los espacios del hábitat: la cuenca del río Alhárabe y los Molinicos (Moratalla)}

El Campo de San Juan, donde se ubica la Umbría, es un altiplano rodeado de altas sierras en contacto ya con las béticas, tradicionalmente dedicado al cultivo de secano y con importantes recursos de pastos y de salinas de interior como el Zacatín. En el Campo de San Juan conocemos algunos rasgos del poblamiento del Bronce o de época romana (Medina, 2013), mientras que no es conocido hasta ahora el poblamiento de época ibérica, salvo algunas dispersiones de material como en las Cuevas de Zaén, todavía por caracterizar.

La Sierra de los Álamos separa el Campo de San Juan de la amplia zona contigua al E, el Llano de Moratalla-Calasparra. Ambos forman parte de los altiplanos del NO murciano. En esta zona, surcada por los ríos Alhárabe, Moratalla y Benamor, se ubica Molinicos, un asentamiento conocido principalmente por las excavaciones de Lillo, a cuya bibliografía remitimos (1993). Molinicos ocupa un pequeño cerro de margas calizas miocenas que buza ligeramente hacia el $\mathrm{S}$, con una altitud máxima de 440 m.s.n.m. y en la confluencia de los ríos Alhárabe y Benamor. Dentro de este Llano de Moratalla-Calasparra, encontramos también otros asentamientos ibéricos ubicados más al este, como el Campillo y el Cabezo de las Juntas.

El asentamiento de Molinicos, parcialmente amurallado, cubre una superficie máxima de 1 ha. Las excavaciones de Lillo permitieron documentar una larga secuencia de ocupación, desde la Edad del Bronce a época ibérica. Lillo situó el fin del asentamiento hacia mediados del s. IV a. C., cuando fue abandonado, al parecer, después de un episodio violento. Vamos a centrarnos en el área que nos interesa subrayar en relación con la Umbría de Salchite.

En el extremo SE del poblado, Lillo y su equipo excavaron la habitación $\mathrm{K}$-sector K-M-L (Fig. 5)-. Lillo (1993: 214) expuso cómo dicha habitación no respondía al esquema recurrente de vivienda, por su morfología irregular y sus dimensiones mayores que las documentadas en el resto del asentamiento. En este espacio K "nada evoca el contexto convencional doméstico hallado en otras casas", con una cultura material caracterizada, en su opinión, por "piezas de exquisita calidad", que imitaban cerámicas griegas y mediterráneas (Lillo, 1993: 212). Entre los materiales conservados subrayamos la presencia de al menos cuatro cráteras de columnas de fabricación regional, fragmentos de kílix, ánforas, morillos, discos de piedra y un vaso de cerámica ática de St. Valentin (Fig. 6). De hecho, deduce que "todo el contexto aparece relacionado con actividades de tipo religioso. Hemos de admitir el marcado carácter ritual que parece emanar de todo el conjunto" (Lillo, 1993: 214). Es interesante en este sentido destacar el hallazgo de algunas hojas de sílex y de un fragmento de cuchillo de bronce, que pudieron estar relacionados con el desmembramiento y descarnamiento de los animales, tal y como se ha constatado en otros contextos rituales (Ferrer, 2013: 225). Otra característica que subrayamos de este espacio es la 


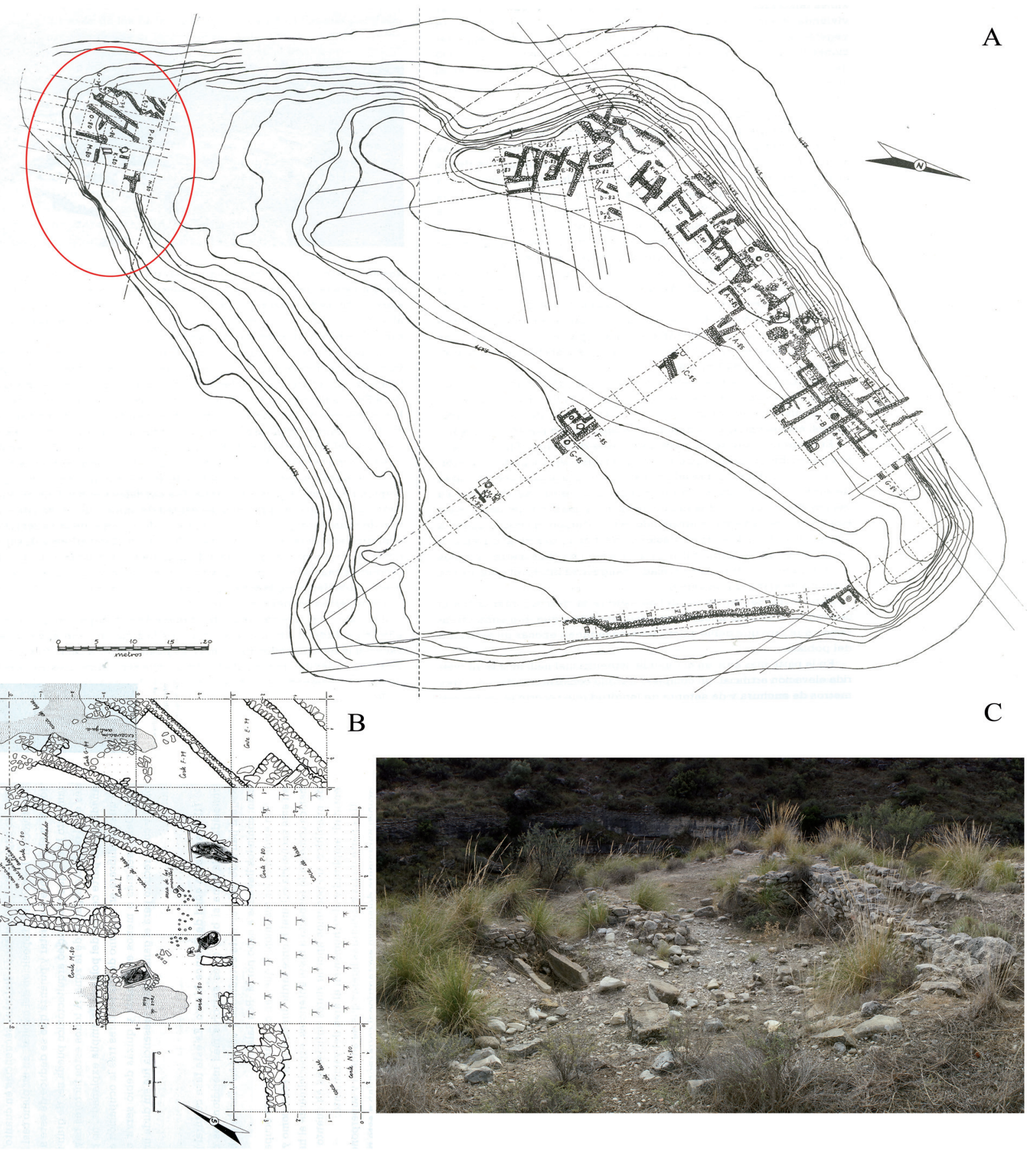

FIG. 5. Molinicos, Moratalla: A) planta con el espacio K marcado (Lillo, 1993); B) detalle ampliado; C) y vista actual del espacio $K$. 

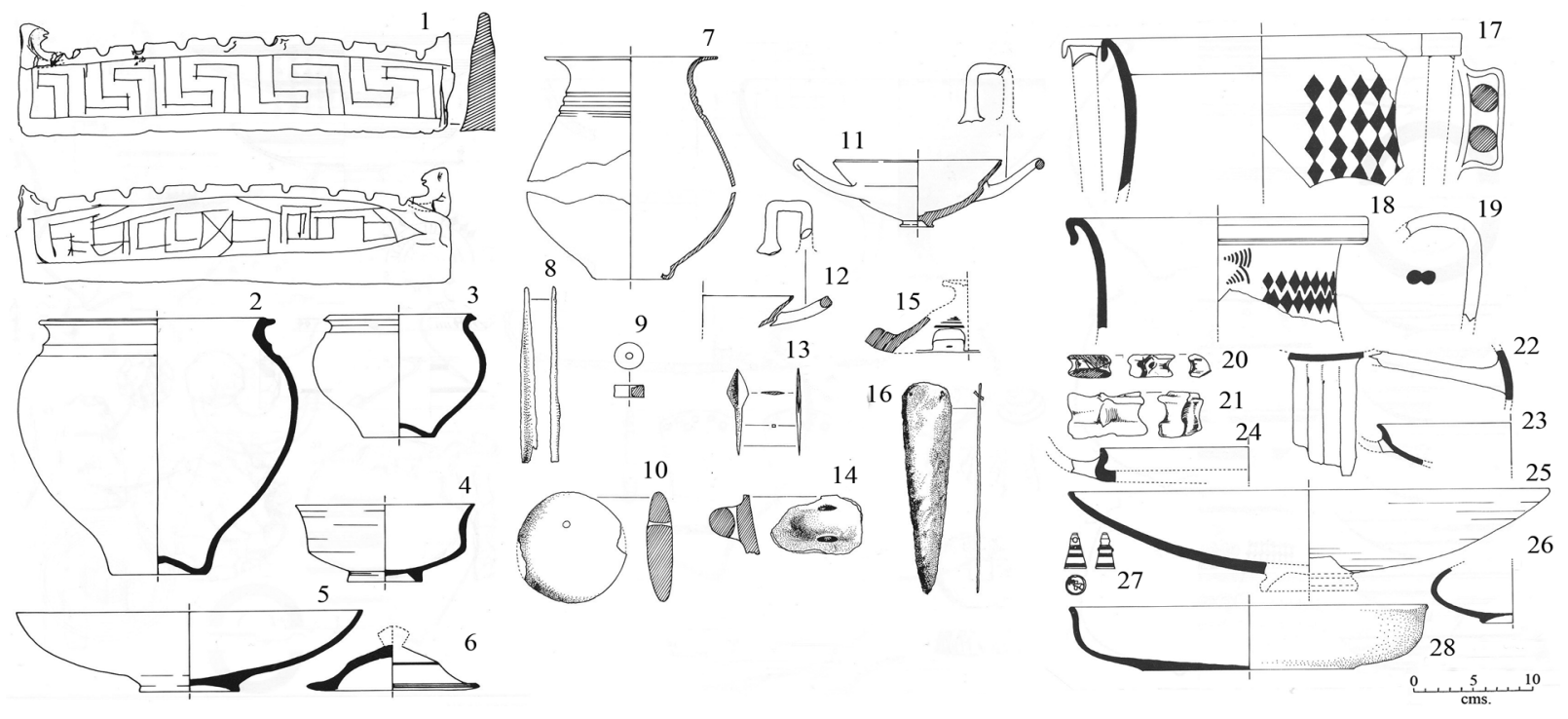

FIG. 6. Cultura material del espacio $K$ de Molinicos (dibujo a partir del original de Lillo, 1993).

presencia de enterramientos, al menos dos inhumaciones en cista y una en pithos (Fig. 6). Aunque Lillo (1993: 214) los calificó de argáricos, en su opinión habrían sido descubiertos y respetados en época ibérica, dejando incluso in situ ajuares que incluían puñales y cuchillos de bronce.

En la parte central de la habitación K se documentó "un considerable número de piezas redondeadas", quizás las ollas ya mencionadas, y "dos urnas globulares de cerámica tosca, de color grisnegro y cuatro fichas circulares de caliza de 60 $\mathrm{mm}$ de diámetro y $18 \mathrm{~mm}$ de grueso" (Maluquer, 1983: 174; Lillo, 1993: 216). En el interior de la urna de mayor tamaño se hallaron dos fragmentos de morillo muy semejantes a los que se habían recuperado antes de las excavaciones oficiales. En ellos nos detendremos brevemente, tras subrayar cómo la posición central de esta cultura material coincide con la habitual de los hogares, que aglutinan y condicionan frecuentemente la distribución y la actividad en el espacio (Gracia, 2001: 102).

Los morillos de Molinicos han sido objeto de estudios a los que remitimos para una visión general (Lillo, 1981: 162; Maluquer, 1983; Almagro y Lorrio, 2011: 331) y que nos permiten detenernos en determinados aspectos (Fig. 7). El morillo n. ${ }^{\circ} 1$ fue hallado antes de las campañas de Lillo. Morfológicamente es plano y rectangular, ensanchado en su base y decorado en sus laterales mediante incisiones con motivos geométricos. Las 10 muescas de su parte superior (Lillo, 1993: 214, lám. XXXVII n. ${ }^{\text {os } 1-2) ~ p e r m i t i r i ́ a n ~ e n c a j a r ~ l a s ~ v a r i l l a s ~ d e s-~}$ tinadas a sostener los alimentos. En uno de sus extremos presenta una figura humana de pie, vestida con un largo manto, con la cabeza cubierta y con los brazos extendidos y apoyados en la parte superior del morillo, en un gesto de sacrificador $\mathrm{u}$ oferente (Maluquer, 1983: 152). El morillo n. ${ }^{\circ} 2$ fue hallado en 1980, durante las excavaciones oficiales; de morfología y dimensiones similares, la figura de su extremo alcanza $84 \mathrm{~mm}$ de alto. Es, de nuevo, una figura humana velada de pie (Maluquer, 1983: 174), con la misma gestualidad que la ya reseñada para el morillo n. ${ }^{\circ} 1$. Representa el mismo traje largo y velo e idéntica posición de los brazos.

Subrayamos este remate superior similar en ambos morillos, consistente en una figura antropomorfa pinzada sobre la arcilla fresca. Se trata de una imagen, identificada como femenina por Maluquer (1983: 174), que se distingue por su busto y brazos elevados (Lillo, 1993: 214). Nuestra hipótesis es que existe una relación entre la figura antropomorfa velada, posiblemente femenina, de los morillos de Molinicos y la figura femenina con túnica de la Umbría de Salchite. Ambas 
aparecen con gesto y vestimenta relacionable y, sobre todo, ambas están vinculadas a un instrumento que permite cocinar, el morillo-brasero y, por tanto, al fuego y a la transformación que este permite. Algunas semejanzas más entre la cultura material del espacio $\mathrm{K}$ de Molinicos y Salchite refuerzan nuestro argumento, como la presencia en ambos contextos de vasos globulares y exvasados (Fig. 6, n. ${ }^{\text {os }} 2,3$ y 7) y de campanillas de bronce (Fig. 6, n. ${ }^{\circ}$ 27), asociadas estas últimas con contextos rituales mediterráneos (Ferrer, 2013) y en ocasiones con la infancia o juventud (Chapa, 2008: 624).

En este contexto resulta interesante subrayar la relación de los morillos y asadores con el hogar y con una cocina ritualizada. La utilización de los morillos en ocasiones especiales se ha argumentado, en parte, por su escasez, por el empleo de materiales particulares, así como por la posibilidad de cocinar a la brasa sin un instrumental específico (Gracia, 2001: 101-103; Almagro-Gorbea y Lorrio, 2011). Los morillos protagonizarían más bien momentos especiales, como en el espacio de reunión y comensalidad suprafamiliar definido en el Puntal dels Llops. Además, el asado en morillos implicaba una serie de pasos específicos, susceptibles de ser pautados socialmente y ritualizados, que abarcaban el preparado, el descuartizamiento, el troceado de la carne y la potencial selección de partes concretas del animal, así como su correcta colocación en el morillo, que debía ubicarse a una altura precisa para ser cocinado correctamente. En algunos casos, como en la Bastida de les Alcusses, y como hipotetizamos también en Molinicos, se ha vinculado el uso de morillos y cazuelas, relacionándose estas últimas con la posible recogida de la grasa durante el asado (Iborra et al., 2010: 109).

Numerosos estudios han relacionado el hogar y el fuego con las formas de vinculación, memoria y cohesión de un grupo familiar, ya sea nuclear o extenso. En contextos suprafamiliares, las prácticas desarrolladas alrededor del fuego tuvieron parte activa no sólo en la construcción de un sentido de grupo o comunidad, sino también en la creación, continua negociación y legitimación de las relaciones sociales y de poder. Este ambiente de la cocina junto al fuego se ha relacionado así con el relato de historias, susceptibles de transmitir los valores que posibilitan y condicionan la propia
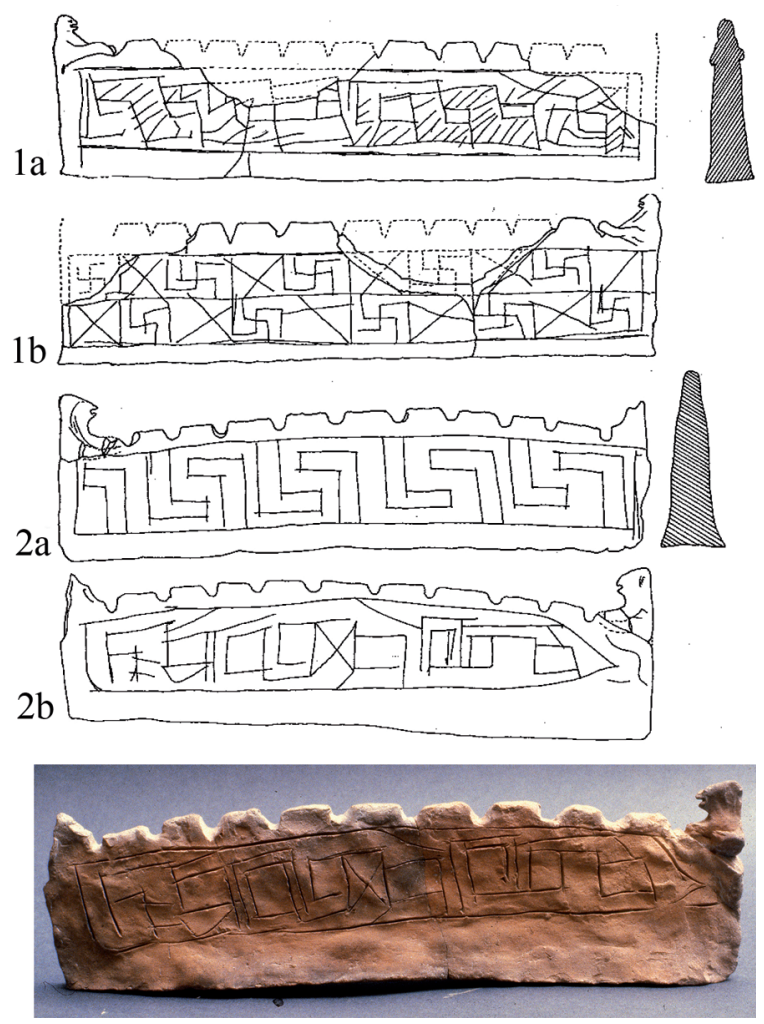

FIG. 7. Morillos de Molinicos (dibujo de Maluquer, 1983) y detalle del morillo n. ${ }^{\circ} 1$.

reproducción de la comunidad. Podemos vincular estos espacios con la transmisión de los posibles mitos articuladores y definidores de un territorio, como en el caso del mito del lobo del Pajarillo en el territorio del Jandulilla (Chapa, 2003).

Por lo tanto y en torno al fuego parecen converger tanto acciones cotidianas como rituales. De hecho, este espacio de Molinicos apunta a la relación e imbricación de las prácticas cotidianas y las actividades rituales, algo sobre lo que insiste el concepto de ritualización (Bell, 1992) y la teoría de la práctica y que nos permite identificar los procesos por los que determinados aspectos de la vida, como puede ser el cocinar, se seleccionan y dan un énfasis especial (Bradley, 2005: 34). El hogar y el fuego son también nexo de unión y elemento clave en la continua definición de la estructura familiar, algo que puede relacionarse asimismo con la idea del culto a los antepasados. De esta forma pudieron identificarse quizás los restos óseos del espacio $\mathrm{K}$ de Molinicos. 


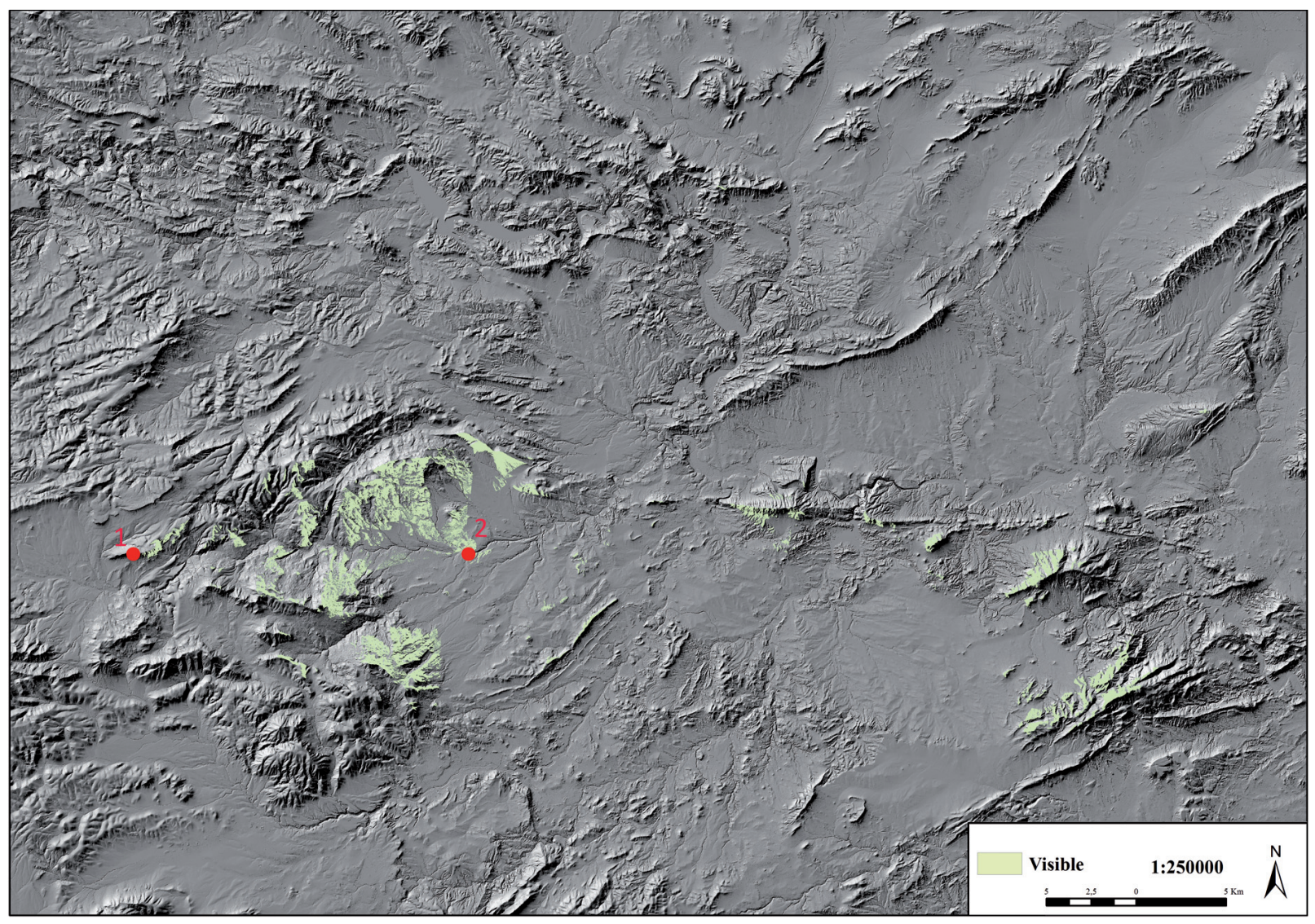

FIG. 8. Visibilidades acumuladas desde Molinicos (2) que incluye el limite oeste en la Umbría de Salchite (1). (C) J. L. Pecharromán, LABTEL, CCHS-CSIC).

Aunque debemos proseguir el análisis de la habitación $\mathrm{K}$ de Molinicos, nuestra propuesta preliminar aquí es la posibilidad de interpretarlo como un espacio de memoria, suprafamiliar. Es un espacio urbanísticamente y morfológicamente diferenciado, con "una extraña y amplia distribución" y, en opinión de Lillo (1981: 29 y 392), el sector con una ocupación más antigua. Además es el punto del asentamiento más cercano a un manantial que surge en una pequeña cascada sobre el cauce del Benamor y que constituye un punto singular en la confluencia de ambos ríos. En esta habitación $\mathrm{K}$ se conoce posiblemente y se respeta la presencia de enterramientos anteriores, quizás interpretados como antepasados. Existen asimismo evidencias de una cultura material diferenciada y de prácticas de comensalidad. Todo ello puede vincularse, como hemos subrayado, con las formas de cohesión del grupo y con las bases que permiten renovar y reproducir sus relaciones sociales y los rasgos distintivos de su identidad. Esto incluye, claro, la definición de los límites del territorio, de dónde comienza un espacio ajeno o saltus donde situar lo sobrenatural y donde confluyen los seres del espacio propio y del espacio salvaje.

Esto nos hace volver al territorio. Desde Molinicos se controla la amplia llanura circundante, vertebrada por los cauces del Benamor y del Alhárabe. La imponente Sierra de los Álamos constituye la frontera visual al E y, entre esta y la Sierra del Cerezo que limita al $\mathrm{N}$, el horizonte visual es el macizo de la Umbría de Salchite. Así pues, subrayamos cómo siguiendo el curso del Alhárabe, el límite visual en el horizonte para la comunidad que habitaba Molinicos era precisamente el macizo de la Umbría de Salchite (Figs. 8 y 11).

De esta forma, Molinicos y la Umbría estaban conectados de una forma doble. Por una parte, por 


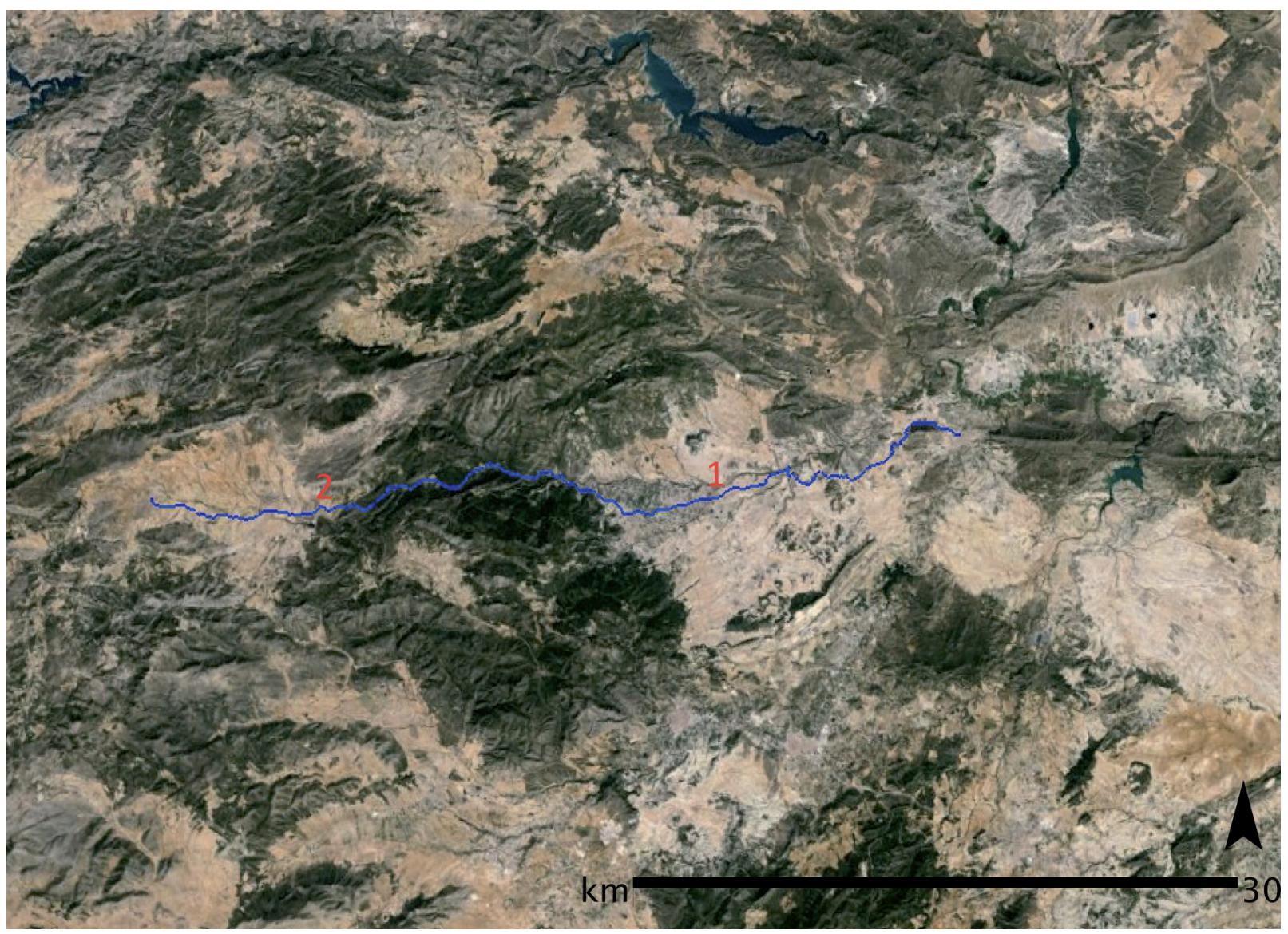

FIG. 9. Itinerario de gran recorrido entre el Llano de Moratalla-Calasparra y el Campo de San Juan por la cuenca del Alhárabe: 1) Molinicos y 2) Umbría de Salchite.

la fuente hídrica, el curso del río Alhárabe. Por otra, porque el horizonte visual de estas comunidades era la montaña de la Umbría de Salchite. De esta forma, la Umbría no sólo era un importante hito visual en el Campo de San Juan, sino también desde los territorios vecinos del E, desde el Llano de Calasparra-Moratalla. De hecho, ambos espacios se vertebran aún mediante una vía tradicional de paso que sigue el cauce del río Alhárabe y que fosiliza parcialmente el sendero de gran recorrido GR-7 (Fig. 9).

\section{El territorio político, diacronía y memoria: el lugar de culto y la apropiación ideológica de un valle de altura}

Hasta ahora aceptamos que Molinicos se despobló a mediados del s. IV a. C. como argumentó
Lillo (1993). Es posible, no obstante, plantear la continuidad del poblamiento en el Llano de Moratalla-Calasparra, donde conocemos algunos asentamientos ibéricos que incluyen secuencias desde el s. IV a época romana, como El Campillo y el Cabezo de las Juntas -ambos en Calasparrao, ya en el término de Moratalla, el Cerro de Santa Quiteria o Moratalla la Vieja, que se sitúan a menos de $5 \mathrm{~km}$ de Molinicos.

Por tanto, y a pesar del muy escaso conocimiento del poblamiento antiguo de esta zona, es posible argumentar la continuidad de las áreas de hábitat en el Llano de Moratalla-Calasparra, en las cercanías de Molinicos. En este ambiente, hipotetizamos el recuerdo y continua reelaboración y reinvención de un relato del que formaría parte un personaje femenino vinculado al fuego. 


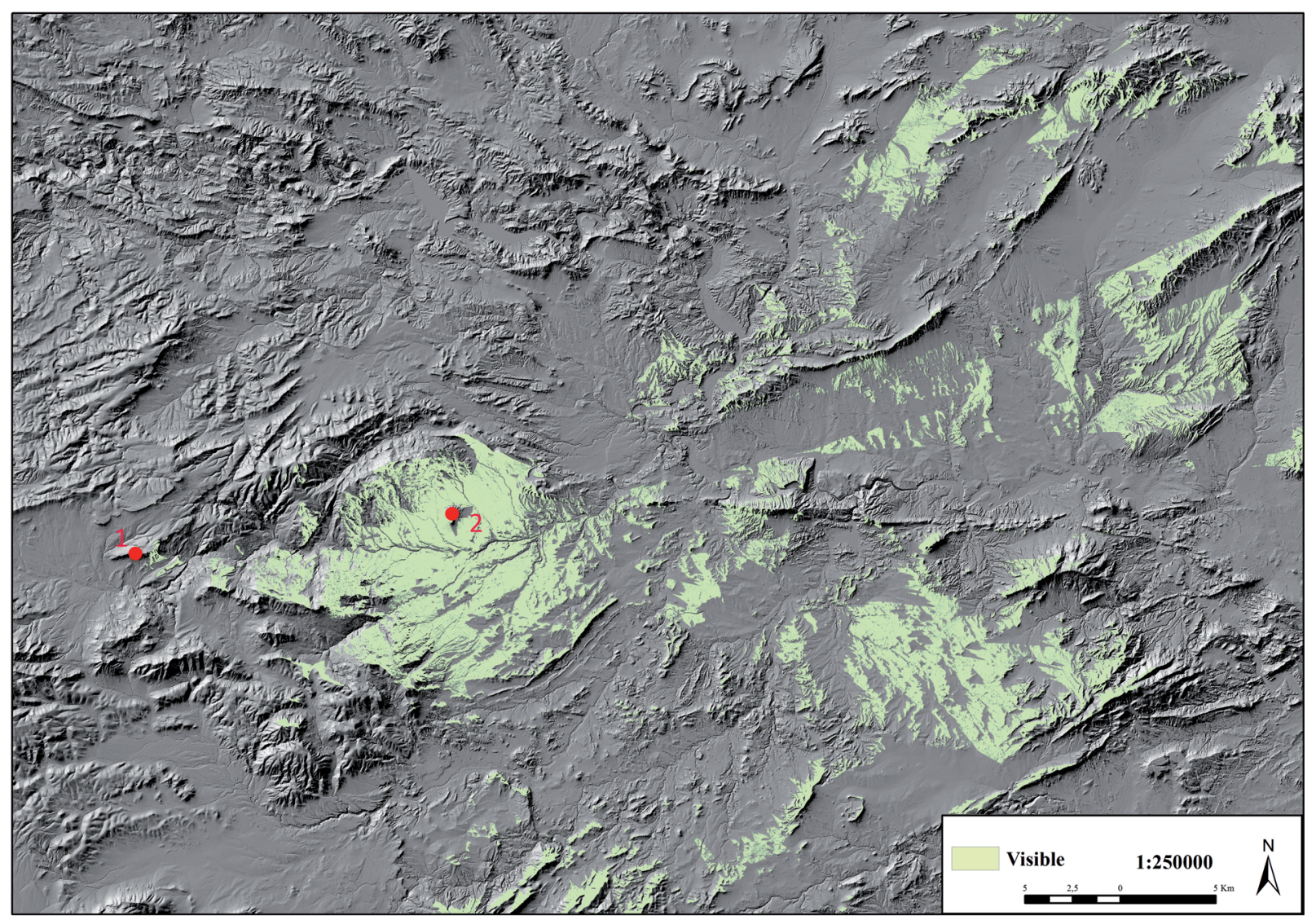

FIG. 10. Visibilidades acumuladas desde el límite O en la Umbría de Salchite (1) y desde Moratalla la Vieja (2) (@) J. L. Pecharromán, LABTEL, CCHS-CSIC).

En el caso de Moratalla la Vieja, se ocupa un cerro aislado a unos $4 \mathrm{~km}$ de Molinicos y que se sobreeleva unos $100 \mathrm{~m}$ sobre el terreno circundante. En él se ha señalado una larga secuencia de ocupación desde la Edad del Bronce a época tardoantigua (Cuadrado, 1947) e incluyendo una fortificación ibérica (Lillo, 1981: 15-16; García Cano, 2008: 13). De momento, caben varias posibilidades sobre las relaciones de vecindad establecidas entre asentamientos tan próximos como Moratalla la Vieja y Molinicos, como un posible proceso de agregación a partir del s. IV a. C.

En cualquier caso, lo que nos importa subrayar es que, aunque con cambios en los puntos concretos ocupados, parece clara la continuidad del poblamiento ibérico en este Llano hasta época romana. Además, desde algunos de ellos como el cerro de Moratalla la Vieja se alcanza un mayor control visual del cauce del Alhárabe y el macizo de la Umbría continúa siendo su horizonte visual (Fig. 10). Por tanto, es posible plantear, aunque preliminarmente, la continuidad del poblamiento en estas cercanías de la confluencia entre el Benamor y el Alhárabe, una cuenca hídrica compartida con el vecino altiplano del Campo de San Juan y con la Umbría de Salchite.

De esta forma, y aunque los restos materiales de la acción humana en el santuario son mayoritariamente, hoy por hoy, coetáneos o posteriores a la conquista romana, su visibilidad desde el poblado de Molinicos y su semejanza con los morillos de este asentamiento hacen que planteemos la vigencia en época ibérica de un modelo ideológico que mantiene como referente visual esa montaña de confín. A su relevancia topográfica indudable, la Umbría suma el haber sido una referencia visual y mnemónica constante, con cualidades morfológicas y cromáticas que la diferencian respecto al resto del 
horizonte visual de las comunidades del Llano de Moratalla. Es, además, una referencia con características orográficas y cromáticas diferenciadas respecto al resto del horizonte visual (Fig. 11). Es decir, la representación de la Umbría, con una figura femenina con atributos tan similares a la de los morillos de Molinicos, y la identificación de estas semejanzas en un territorio hídrico visualmente conectado nos hacen plantearnos la vigencia y posible reinvención, en la comunidad que ocupa la cuenca del Alhárabe, de un relato concreto protagonizado por esta figura femenina, por el fuego y por prácticas realizadas en torno a los morillos-braseros.

Como hemos especificado antes, nuestro argumento no implica defender la transmisión de un relato con contenido fijo, sino su necesaria y continua reelaboración dentro de procesos y relaciones sociales cambiantes. El habitus de quienes participan en las prácticas rituales se caracteriza por un proceso continuo de interpretación, reinterpretación y cambio (Verhoeven, 2011: 123). Desde esta perspectiva, el ritual no reproduce las normas existentes sino, más bien, cómo estas se negocian a cada momento. El mito, como su representación iconográfica, tiene capacidad de mutar y adoptar significados diversos dependiendo del contexto. De hecho, la fabricación de estos grandes vasos figurados de la Umbría, de los que los fragmentos figurados habrían formado parte, y su reparación mediante las lańas documentadas en el santuario nos permiten vislumbrar la importancia de ciertas prácticas que posibilitarían el recuerdo y la constante reinvención del relato. Como se ha señalado en otros contextos, las prácticas de inscripción, como la realización de una decoración figurada en estas grandes urnas, median en los procesos de reproducción social y refuerzan las relaciones entre lugares y memoria (Jones, 2007).

En el modelo ideológico que planteamos para este territorio, en el mito que lo transmitió y al que pudieron vincularse las representaciones humanas de la Umbría y Molinicos, identificamos varios elementos recurrentes: la figura femenina velada, el brasero-morillo, el fuego como elemento transformador que enlaza con las prácticas domésticas cotidianas y la materia orgánica que se cocinaría en el morillo. Otros elementos aparecen tan sólo en la representación cerámica de la
Umbría: las aves, los carnívoros y el árbol o elemento vegetal. Estos últimos aparecen en otras imágenes iberas de ámbitos rituales y liminales, como en el caso ya señalado de la divinidad alada de Cerro Gil, donde carnívoros, aves y plantas rodean a la diosa híbrida en un lugar liminal, ante el umbral de la muerte. Podemos destacar la recurrencia de los carnívoros, presentes tanto en la cultura material como en la representación de la Umbría y ampliamente relacionados en el registro ritual o liminal ibérico.

La Umbría pudo percibirse así como un espacio liminal y agreste para las comunidades del contiguo Llano. Las cuevas, percibidas como lugares liminales entre mundos diversos, han sido lugares apropiados para relacionarse con divinidades y fuerzas sobrenaturales por sus características que modifican y alteran la percepción sensorial habitual (Bradley, 2002; López-Bertrán, 2011: 87).

Conviene recordar aquí la existencia de otros fragmentos figurados provenientes de La Nariz que, aunque escasos, recogen más representaciones de aves y otro personaje con los brazos elevados (Fig. 4) que nos indican la existencia de un desarrollo figurativo mayor en la iconografía de la Umbría, y la presencia de un gesto de brazos elevados que puede relacionarse con otras escenas de ámbitos cercanos, como la del Cerro del río Turrilla. No podemos descartar, por tanto, que las imágenes del santuario albergasen escenas con mayor desarrollo, quizás de celebraciones y presentación ante la divinidad.

Por todo ello, la hipótesis que presentamos aquí es que la figura femenina con atributos sagrados, vinculada al fuego y flanqueada por aves y carnívoros, está en nuestro ejemplo relacionada con dos espacios de memoria, como posiblemente fueron la habitación $\mathrm{K}$ de los Molinicos y la Umbría de Salchite. Su evocación se habría realizado en el marco de determinadas prácticas rituales, parte de las cuales al menos tuvieron como protagonistas el agua, recogida en las piletas de las cuevas de la Umbría, el fuego, vinculado al morillo/brasero, y la materia orgánica cocinada. Unas prácticas que se concretaron quizás en actividades como la libación, la ofrenda y el cocinado de alimentos y que, en parte, pudieron desarrollarse en las ollas globulares constatadas tanto en la Umbría como en Molinicos. 
Estas habrían sido al menos parte de las prácticas rituales que pudieron desarrollarse en el lugar liminal o saltus de la Umbría de Salchite. Lejos de ser lugares poco frecuentados, estas prácticas se conciben dentro de paisajes bien conocidos, marcados mediante prácticas rituales que implican la apropiación del territorio y definen la identidad social de la comunidad (Taçon, 1994; López-Bertrán, 2011: 95). Así, la Umbría pudo ser un lugar propicio para prácticas relacionadas con la identidad social, como la iniciación en que mediarían personajes humanos o divinidades (González-Alcalde y Chapa, 1993). Como en otras representaciones iconográficas del mundo ibérico, la iniciación social parece situarse en el espacio salvaje, donde es preciso vencer diferentes pruebas mediante la habilidad y la astucia (Schnapp, 1997; Grau y Olmos, 2005; Olmos, 2008).

La repetición es otra de las prácticas fundamentales para el recuerdo y la continuidad de un relato ideológico. Una repetición que no es sólo verbal, sino también corporal, y que se introduce de diferentes formas en el habitus de la comunidad. En este sentido, hemos mencionado la vía tradicional que siguiendo el curso del Alhárabe une la zona de Molinicos-Moratalla y el Campo de San Juan. En ella constatamos ciertas evidencias de un poblamiento antiguo, como el poblado de la Risca (López, 1991). A través del movimiento por esta vía se construiría un sentido de lugar: los espacios sagrados serían puntos clave dentro de estas vías de paso al inmediato altiplano $y$, de esta forma, los movimientos cotidianos de acceso a las altas tierras colindantes podrían haberse ritualizado. El peregrinaje al santuario, quizás con motivo de determinadas celebraciones estacionales, sería sin duda un elemento importante en la connotación cultural de los paisajes. Así, mediante el acto de caminar, las comunidades transformaron el espacio diario en un paisaje connotado.

Concibiendo el ritual como un tipo de práctica definida por convenciones propias, como una forma de acción social (Bradley, 2005: 33), podemos argumentar el importante papel que acciones como el cocinar y la libación habrían tenido dentro de las prácticas de ritualización llevadas a cabo en el santuario. Estas prácticas se han vinculado con peticiones de propiciación y fertilidad, así como con posibles ritos de iniciación social, todos ellos relacionados con una frecuentación estacional del santuario quizás vinculada a determinadas épocas del año, tal y como se ha argumentado por ejemplo en el caso de Es Culleram respecto a la celebración del comienzo de la primavera (Costa, 2007: 18).

En los últimos años, y a un nivel más general, la investigación de la Edad del Hierro en el área mediterránea peninsular ha insistido en el análisis de los posibles procesos de territorialización por los que determinados centros delimitaron el ámbito de sus dominios. Estos fenómenos, de definición social del territorio y de sus confines, demuestran la vinculación de la comunidad a su territorio (Grau y Segura, 2013: 43). En la comarca de Alcoy (Alicante) se ha analizado cómo los relieves periféricos de lo visible codificarían culturalmente la polaridad entre lo propio y lo ajeno. Cada comunidad establecería claramente los límites de su territorio en el perfil de las montañas (Grau y Segura, 2013: 43-45; Grau, 2013: 280). A partir del s. IV a. C. se han identificado experiencias destinadas a modificar el territorio agrario del oppidum más allá de los límites tradicionalmente controlados por este. Para ello nada mejor que sustituir el factor visibilidad, dominante hasta ese momento para la apropiación del espacio, por un elemento nuevo y tradicional, los cursos de agua (Ruiz, 2008: 828).

El análisis que hemos realizado pone de relieve cómo pudieron tener lugar estos procesos en esta área del NO murciano, en que la Umbría evidenció los confines territoriales de la comunidad local. La Umbría constituía ese horizonte visual cotidiano, ese contraste ofrecido por la línea de montańas que es la frontera ecológica definida por Ruiz y Molinos (2008: 54). Imponente dentro del Campo de San Juan, el macizo de la Umbría habría sido un punto de referencia clave para la orientación, para la creación de mapas cognitivos y para las formas de apropiación del espacio por parte de una comunidad política.

Nuestra hipótesis es que en la cuenca del Alhárabe los límites físicos de lo visible se habrían convertido en los contornos del espacio social de las comunidades iberas del área de Moratalla. Este caso aúna el cauce fluvial con la frontera que marca el espacio visible. El territorio del Alhárabe conjugó ambas: el eje del río pudo marcar la 
expansión del espacio apropiado hacia el o, más allá del valle del asentamiento. Sin embargo, la materialización ideológica de esa apropiación se fijó en un confín visible desde el hábitat, eligiendo para ello una montaña que, dentro del horizonte visible desde el área de Molinicos, poseía una morfología y un cromatismo singular (Fig. 11). En esta elección identificamos 3 factores: por una parte, la perceptibilidad desde el área de asentamiento, configurándose como una frontera ecológica; por otra, su ubicación fuera del valle en que tiene lugar el hábitat, expandiendo por tanto el territorio controlado más allá de las sierras más cercanas; $y$, por último, su cercanía respecto al curso fluvial que vertebra el territorio. De esta forma, en el Alhárabe se define culturalmen-

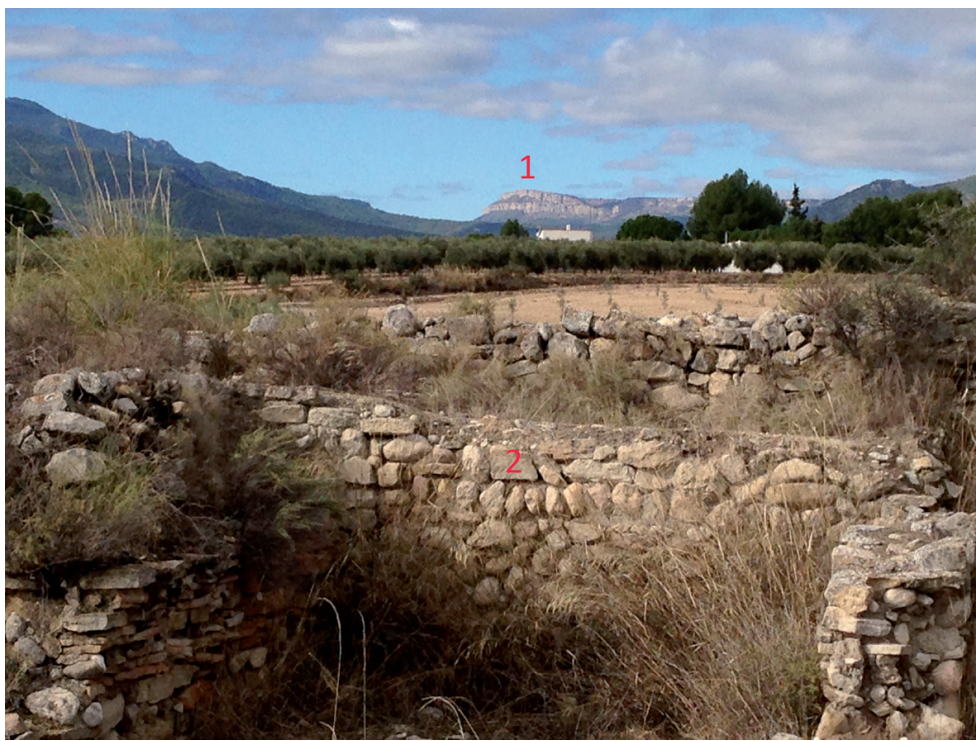

FIG. 11. La Umbría de Salchite (1) diferenciada en el horizonte visual de Molinicos (2). te un confín ubicado más allá de lo que serían el ager-terrenos cultivables de las vegas y llanos de Moratalla- y saltus -espacio salvaje de la alta Sierra de los Álamos- más cercanos al hábitat. Es posible que la apropiación implique definir un nuevo espacio de aprovechamiento más allá de esta primera sierra, llegando al territorio más elevado que es el altiplano del Campo de San Juan.

En este sentido es interesante apuntar la posible complementariedad económica que podía suponer la apropiación de las altas planicies del valle de la Umbría de Salchite. Mientras que las alturas medias en el área de Moratalla oscilan entre 400-500 m.s.n.m., el fondo de valle del Campo de San Juan está a 1066/1050 m.s.n.m., a lo que habría que sumar las altas sierras circundantes. Esta diferencia de altitud, que se plasma en diferencias claras en los pisos de vegetación, pudo implicar un aprovechamiento escalonado entre ambos territorios y ser el Campo de San Juan un valle estacionalmente utilizado. Aunque es preciso comprobar este argumento paleoambientalmente, los análisis realizados, hasta el momento, apuntan a un uso del suelo prioritariamente dedicado a pastos hasta época romana, lo que podría indicar un sistema de explotación de escalones estacionales, tal y como se ha analizado en otras áreas de montaña (Groetzbach, 1988: 26;
Carrión et al., 2004). Esta posible dedicación complementaria pudo ser parte del interés y de la necesidad de apropiación, material y simbólica, de las altas tierras situadas al o de los asentamientos principales del Llano de Moratalla-Calasparra.

Es posible reconocer ciertos rasgos definidores de este territorio a lo largo de una larga diacronía. De hecho, la mayoría de materiales conocidos hoy de la Umbría se adscriben a un momento posterior a la conquista romana. En nuestra opinión, esto indica la vigencia del lugar y de prácticas sociales llevadas a cabo en la Umbría, aunque se trata de prácticas comprensibles en el nuevo contexto abierto tras la conquista romana. Recientes trabajos han permitido acercarnos a las estrategias de implantación y control territorial romano en áreas cercanas del SE peninsular, que conllevaron el control de ciertos valles a través de castella republicanos como los ubicados en Archivel y Barranda. Sin embargo, desconocemos todavía en gran medida los aspectos concretos de la implantación romana en amplias zonas del NO murciano, aunque existen argumentos sobre la reestructuración del modelo anterior ibérico (Brotons y López, 2010).

Mientras avanzamos en el conocimiento más concreto de este modelo de ocupación de época romana, nos interesa subrayar la aportación de la 
cultura material y las prácticas de memoria en los momentos de ruptura, cuando un nuevo orden social desafía al antiguo. Halbwachs (1992) subrayó cómo la memoria disfraza las rupturas creando la apariencia de continuidad y de un todo social sin fisuras. En este contexto son comprensibles los fenómenos de reinvención del pasado, en los que la continuidad de elementos anteriores, como de nuestra figura femenina velada, no es mera supervivencia sino una renovación y quizás incluso una 'resistencia' hacia Roma, especialmente por parte de las élites locales, que implica la construcción de nuevas identidades locales (Van Dommelen, 1998: 30, 42-44; Crawley-Quinn, 2012: 449). La II Guerra Púnica y la posterior conquista romana crean contextos de cambio y reinvención, en que es preciso renegociar las relaciones sociales. En este nuevo horizonte, una de las maneras en que las desigualdades sociales heredadas pudieron reconstruirse, legitimarse y quizás mantenerse es a través de las prácticas llevadas a cabo en lugares de identidad como debió ser la Umbría de Salchite. En la diacronía, estos lugares aparecen como palimpsestos donde puede reinscribirse sin cesar el juego intrincado de la identidad y de la relación.

Este contexto de reinvención de la tradición es adecuado para la elaboración de vasos de memoria, figurados con antiguos mitos recreados y adaptados al nuevo contexto, vasos con figuraciones mnemotécnicas, lañados y utilizados repetidamente en prácticas como las que motivaron la frecuentación del santuario de la Umbría de Salchite. Su fabricación y uso, junto a otros fenómenos como la utilización de reliquias, pretenderían objetivar un pasado ancestral colectivo (Lillios, 1999). Estos vasos figurados constatados en la Umbría actuarían, en nuestra opinión, dentro del campo simbólico definido por Bourdieu (1972, que alcanza una importancia clave en las relaciones sociales ya que permite anular la arbitrariedad de las acciones y las transforma en una situación natural. De hecho, la memoria coexiste siempre con el olvido en los procesos sociales mediante los cuales el pasado es reconstruido, consumido, borrado y desmantelado. Por ello, el grupo que tiene el capital simbólico tiene la capacidad de construir la verdad e imponer una determinada visión de lo social. Estos procesos de reinvención y negociación abiertos tras la conquista romana pueden ayudarnos a explicar, en nuestra opinión, por qué el santuario adquiere en este momento una mayor densidad ritual (Bell, 1997; Grau y Amorós, 2013) o frecuentación. Y aunque siempre es más fácil ver las maniobras top-down de las élites que utilizan la memoria para sus fines, es preciso recordar cómo la memoria se emplea también en la resistencia, pudiendo coexistir versiones conflictivas de acontecimientos, utilizadas por grupos que plantean la contestación en un momento dado. Así podría verse quizás la continuidad de un límite en la Umbría, discordante con las fronteras administrativas y políticas que Roma va implantando.

\section{A modo de conclusiones}

En general, planteamos que el proceso que hemos analizado en las páginas precedentes se ajustaría a una apropiación territorial, que aúna la base pagánica (Ruiz, 2007: 828) con la frontera ecológica al definirse mediante la visibilidad. Es una construcción territorial que implica la sacralización del límite existente entre asentamientos fortificados y cercanos a una hectárea, como Molinicos. El margen que se elige es un área de cuevas ubicada en la montaña que es parte del horizonte visual del poblado y que coincide además con el eje que supone el cauce fluvial del Alhárabe, que marcaría el territorio definido. La diferencia entre el contexto arqueológico del s. IV a. C. de Molinicos y del II-I a. C. reconocido hoy para la Umbría permite plantear la diacronía y constante reformulación de un modelo ideológico sujeto a un proceso de memoria en el que debemos profundizar más.

Esta hipótesis que planteamos respecto a la construcción de un territorio en la cuenca del río Alhárabe permite establecer comparaciones con los procesos analizados en otros territorios del mundo ibérico, en los que se ha adaptado el concepto de pagus definido por Torelli para la modelización de las relaciones territoriales iberas (Ruiz et al., 2001; Ruiz, 2009). En el caso del Pajarillo y del río Jandulilla se ha constatado un proceso de construcción territorial y memoria, por el que cuando la antigua Úbeda emite moneda en el s. II con el nombre de Iltiraka todavía muestra en el 
anverso la imagen de un lobo salvaje aludiendo al mito del territorio (Molinos et al., 1998). En el caso del curso medio y alto del Serpis, Grau (2013) ha definido un proceso en el que, hacia la segunda mitad del s. V a. C., se advierten también las primeras apropiaciones de tipo pago, con la sacralización de los límites mediante cuevas-santuario.

Es preciso recordar el carácter preliminar del estudio de nuestro territorio, por lo que consideramos estas páginas como una primera propuesta de cómo pudo producirse la apropiación ideológica de este territorio y su evolución diacrónica. Es necesario profundizar en la definición de este proceso, así como en su especificidad o semejanza con los ya analizados, como los interesantes procesos de monumentalización de determinados santuarios ibéricos en época romana (Ramallo et al., 1998). En cualquier caso, nuestra hipótesis permite, en nuestra opinión, avanzar más allá del argumentado carácter supraterritorial e inconexo de la Umbría respecto al poblamiento de la zona: el santuario estaría vinculado a una construcción ideológica del paisaje llevada a cabo por grupos sociales concretos, ubicados en el inmediato Llano de Moratalla-Calasparra.

En nuestra opinión, el territorio político del Alhárabe es una construcción social llevada a cabo por determinados grupos, una ideología que podemos suponer extendida después al conjunto social. Resulta sumamente interesante constatar cómo esta construcción ideológica requiere la confluencia de varios elementos: las características físicas y la morfología del paisaje -orografía, cuenca hídrica y horizonte visual-, los espacios del hábitat, la connotación y codificación de los lugares liminales y una serie de prácticas que conllevan una cultura material, unos tiempos y unos relatos específicos. Una vez formulado, el territorio político necesita renovarse continuamente mediante prácticas compartidas y aceptadas socialmente. A ello servirá el recuerdo de los relatos, la repetición de actividades físicas como la cocina y el peregrinaje hacia el santuario. Todo ello es parte de la constante renovación y reinvención del habitus de la comunidad.

En la diacronía, el territorio del Alhárabe nos permite explorar la materialización de las formas por las que ciertos grupos o comunidades negociaron su propio pasado mientras elaboraban su futuro. Más allá de su original formulación por determinados sectores sociales, el relato legitimador es capaz de sobrevivir y reinventarse cuando Molinicos se abandona. Su larga diacronía apunta a su maleabilidad y a su potencial uso estratégico dentro de dinámicas sociales cambiantes. Como se ha argumentado para otros contextos europeos, los rituales son efectivos porque pueden ser reinterpretados. En el caso de la cuenca del Alhárabe, el territorio político debía incorporar los cambios en las relaciones sociales y de poder, reinventando siempre el sentido de ser una comunidad mediante prácticas que forjaban la identidad y estructuraban al grupo humano. Es posible que, mientras tenga validez una forma determinada de aproximarse y de explotar el territorio, mientras continúen determinadas 'visiones del mundo', el relato del límite del territorio pueda seguir existiendo. Siempre cambiante, el relato dará a las nuevas prácticas la legitimidad ficticia de la tradición e intentará cohesionar a una comunidad variable, en nuevos contextos de negociación de las relaciones de poder, mediante la memoria de su común pertenencia a un territorio con ideas y prácticas compartidas.

\section{Bibliografía}

Alcock, S. E. (2002): Archaeologies of the Greek Past: Landscapes, Monuments, and Memories. Cambridge: CUP.

Alcock, S. E. y VAn DyKe, R. (2003): Archaeologies of Memory. Malden: Wiley-Blackwell.

Almagro-Gorbea, M. (1997): "Lobo y ritos de iniciación en Iberia". En Olmos, R. y Santos, J. A. (eds.): Iconografía ibérica, iconografía itálica. Propuestas de interpretación y lectura. Madrid: UAMCSIC, pp. 103-127.

Almagro-Gorbea, M. y Lorrio, A. (2011): Teutates: el héroe fundador y el culto heroico al antepasado en Hispania y en la Keltiké. Madrid: RAH.

Aranegui, C. (2004): "A propósito del vaso de los guerreros del Castellar de Oliva (Valencia)", Anales de la Universidad de Murcia, 17-18, pp. 229-238.

BeLl, C. (1997): Ritual: perspectives and dimensions. Oxford: OuP.

Boric, D. (ed.) (2010): Archaeology and Memory. Oxford: Oxbow Books.

Bourdieu, P. (1972): Esquisse d'une théorie de la pratique. Génève: Édit. Droz. 
BRADLEY, R. (2000): An archeology of natural places. London: Routledge.

BRADLEY, R. (2002): The past in prehistoric societies. London: Routledge.

BRADLEY, R. (2005): Ritual and domestic life in prehistoric Europe. London: Routledge.

BRotons, F. y LÓPez MondÉJAR, L. (2010): "Poblamiento rural romano en el Noroeste murciano". En Noguera, J. M. (ed.): Poblamiento rural romano en el sureste de Hispania: 15 años después. Murcia, pp. 413-438.

Brotons, F. y Ramallo, S. F. (2010): "Ornamento y símbolo: las ofrendas de oro y plata en el santuario ibérico del Cerro de la Ermita de la Encarnación de Caravaca”. En Tortosa, T.; Celestino, S. y CAzorla, R. (eds.): Debate en torno a la religiosidad protohistórica. Anejos de Archivo Español de Arqueología, 55. Madrid: CSIC, pp. 123-168.

Burillo, F. (2007): Los celtiberos. Etnias y estados. Barcelona: edit. Crítica.

Carrión, J. S.; Yll, E. I.; Willis, K. J. y SÁnchez GómEZ, P. (2004): "Holocene forest history of the eastern plateaux in the Segura Mountains (Murcia)", Review of Palaeobotany and Palynology, 132 (3), pp. 219-236.

http://dx.doi.org/10.1016/j.revpalbo.2004.07.002

Cartledge, P. (1979): Sparta and Lakonia. A regional history 1300-362 BC. London: Routledge \& Kegan Paul.

http://dx.doi.org/10.4324/9780203472231

Chapa, T. (2003): "La percepción de la infancia en el mundo ibérico", Trabajos de Prehistoria, 60 (1), pp. 115-138.

CHAPA, T. (2008): "Presencia infantil y ritual funerario en el mundo ibérico". En GuSI, F.; Muriel, S. y OLÀRIA, C. R. (coords.): Nasciturus, infans, puerulus vobis mater terra: la muerte en la infancia. Castellón: Diput. de Castellón, pp. 619-642.

Costa, B. (2007): Es Culleram. 100 anys/años. Ibiza.

Crawley-QuinN, J. (2012): "Fenicios ilusorios en el Mediterráneo central”. En MORA, B. y Cruz, G. (coords.): La etapa neopúnica en Hispania y el Mediterráneo centro occidental. Sevilla: Univ. de Sevilla.

CuAdrado, E. (1947): "La expansión de la Cultura del Argar a través de Murcia", Boletín Arqueológico del Sudeste Español, 3, pp. 66-72.

Fentress, J. y Wickham, C. (1992): Social Memory. Oxford: Blackwell.

Ferrer, M. (2013): "Feasting the Community: Ritual and Power on the Sicilian Acropoleis $\left(10^{\text {th }}-6^{\text {th }}\right.$ centuries BC)", Journal of Mediterranean Archaeology, 26 (2), pp. 211-234.
García Cano, J. M. (1997): Las necrópolis ibéricas de Coimbra del Barranco Ancho (Jumilla, Murcia). Murcia: Univ. de Murcia.

García CANo, J. M. (2008): "Las fortificaciones ibéricas en la región de Murcia", Murgetana, 119, pp. 9-36.

García CARDiel, J. (2013): "De la hierogamia a la ofrenda. El contacto con la divinidad en el mundo ibérico", Mediterraneo Antico, XVI (I), pp. 277-308.

GonZÁleZ-AlCALDE, J. (2005): "Cuevas-refugio y cuevas-santuario ibéricas en la región de Murcia", Verdolay, 9, pp. 71-94.

GonZÁleZ-AlCALDE, J. (2006): "Totemismo del lobo, rituales de iniciación y cuevas-santuario mediterráneas e ibéricas", QPAC, 25, pp. 249-269.

GONZÁLEZ-AlCALDE, J. (2011): "Una reflexión genérica sobre el sacerdocio ibérico en el contexto de las cuevas-santuario", Recerques del Museu d'Alcoi, 20, pp. 137-150.

GonZÁlez-Alcalde, J. y Chapa, T. (1993): “'Meterse en la boca del lobo'. Una aproximación a la figura del 'Carnassier' en la religión ibérica', Complutum, 4, pp. 169-174.

GONZÁLEZ REYERO, S. (2012): "Under divine wings: Forms of territorial and ideological domination during the Iberian Iron Age", Oxford Journal of Archaeology, 31 (3), pp. 261-281. http://dx.doi.org/10.1111/j.1468-0092.2012.00389.x

Gracia, F. (2001): "El fuego como referente de culto. Datos de la Protohistoria peninsular mediterránea", Cypsela, 13, pp. 99-120.

GRAU, I. (2002): La organización del territorio en el área central de la Contestania ibérica. Alicante: Univ. de Alicante.

GraU, I. (2007): "Dinámica social, paisaje y teoría de la práctica. Propuestas sobre la evolución de la sociedad ibérica en el área central del oriente peninsular", Trabajos de Prehistoria, 64 (2), pp. 119-142.

GRAU, I. (2010): "Paisajes sagrados del área central de la Contestania ibérica". En Tortosa, T. y Celestino, S. (eds.): Debate en torno a la religiosidad protohistórica. Anejos de Archivo Español de Arqueología, LV. Madrid: CSIC, pp. 101-122.

Grau, I. (2013): "Síntesis. El Puig y el paisaje de los 'oppida' en las montañas de la Contestania”. En Grau, I. y Segura, J. M.: El oppidum ibérico de El Puig d'Alcoi: asentamiento y paisaje en las montañas de la Contestania. Alcoy: Ayto. de Alcoy, pp. 259-290.

GrAU, I. y AMORÓs, I. (2013): "La delimitación simbólica de los espacios territoriales ibéricos: el culto en el 
confín y las cuevas-santuario". En RísQuez, C. y RUEDA, C. (eds.): Santuarios iberos: territorio, ritualidad y memoria. Jaén: Univ. de Jaén, pp. 183- 212.

Grau, I. y Olmos, R. (2005): "El ánfora ática de la Cova dels Pilars (Agres, Alicante): una propuesta de lectura iconográfica en su contexto espacial ibérico", Archivo Español de Arqueología, vol. 78, n. ${ }^{\circ}$ 191-192, pp. 49-77.

Grau, I. y Segura, J. M. (2013): "Localización geográfica. La Canal: un paisaje de montaña media mediterránea". En GraU, I. y SEgUra, J. M.: El oppidum ibérico de El Puig d'Alcoi: asentamiento y paisaje en las montañas de la Contestania. Alcoy: Ayto. de Alcoy, pp. 41-46.

GrÖTZBACH, E. (1988): "High Mountain as human habitat". En Allan, N. J. R.; KNAPP, G. W. y Stadel, C. (eds.): Human Impact on Mountains. Totowa: Rowman and Littelfield, pp. 14-26.

Halbwachs, M. (1992): On Collective Memory. Chicago.

Iborra, M. ${ }^{a}$ P.; Mata, C.; Moreno, A.; Pérez Jordá, G.; QuiXal, D. y Vives-FerRándiz, J. (2010): "Prácticas culinarias y alimentación en asentamientos ibéricos valencianos". En De la cuina a la taula. Saguntum Extra, 9. Valencia, pp. 100-115.

InsolL, T. (2011): "Ritual and Religion in Archeological Perspective". En Insoll, T. (ed.): The Oxford Handbook of the Archaeology of Ritual and Religion. Oxford: OuP, pp. 1-5.

Jones, A. (2007): Memory and Material Culture. Cambridge: CUP.

http://dx.doi.org/10.1017/CBO9780511619229

Jones, A.; Pollard, J.; Gardiner, J.; Allen, M. J. y BRADLEY, R. (2012): Image, memory \& monumentality: archaeological engagements with the material world. Oxford: Oxbow Books.

LiLlios, K. (1999): "Objects of memory: the ethnography and archaeology of heirlooms", Journal of Archaeological Method and Theory, 6 (3), pp. 235-262.

http://dx.doi.org/10.1023/A:1021999319447

Lillios, K. y Tsamis, V. (eds.) (2010): Material mnemonics: everyday memory in prehistoric Europe. Oxford: Oxbow Books.

Lillo, P. (1981): El poblamiento ibérico en Murcia. Murcia: Univ. de Murcia.

LiLlo, P. (1983): "Una aportación al estudio de la Religión Ibérica: La Diosa de los Lobos de La Umbría de Salchite, Moratalla (Murcia)". En XVI Congreso Nacional de Arqueología. Zaragoza: Univ. de Zaragoza, pp. 769-787.

Lillo, P. (1993): El poblado ibérico fortificado de Los Molinicos. Moratalla (Murcia). Murcia: Ed. Regional de Murcia.
LóPEz García, P. (ed.) (1991): El cambio cultural del IV al II milenios a. C. en la comarca noroeste de Murcia. Madrid: CSIC.

LóPeZ-Bertrán, M. (2011): "Practical Movements: Kinetic Rituals in the Ancient Western Mediterranean", Journal of Mediterranean Archaeology, 24 (1), pp. 85-109.

http://dx.doi.org/10.1558/jmea.v24i1.85

http://dx.doi.org/10.1558/jma.v24i1.85

MaluQuer de Motes, J. (1983): "Morillos del poblado de Los Molinicos, en Moratalla (Murcia)". En Homenaje al prof. M. Almagro Basch. Madrid: Ministerio de Cultura, vol. 2, pp. 171-176.

Medina, A. J. (2013): "La edad del Bronce en el Campo de San Juan (Moratalla)", Revista de la Sociedad de Estudios Historiológicos y Etnográficos de las Tierras Altas del Argos, Quipar y Alhárabe, 5, pp. 4-11.

Molinos, M.; Chapa, T.; Ruiz, A.; Pereira, J.; RísQuez, C.; Madrigal, A.; Esteban, A.; Mayoral, V. y LLORENTE, M. (1998): El santuario heroico de 'El Pajarillo', Huelma, Jaén. Jaén: Univ. de Jaén.

Moneo, T. (2003): Religio Iberica. Santuarios, ritos y divinidades (siglos VII-I a.C.). Bibliotheca Archaeologica Hispana, 20. Madrid: RAH.

OCHARÁN, J. A. (2013): "Santuarios rupestres ibéricos en la Bastetania oriental. Aproximación a los posibles loca sacra libera de la Región de Murcia", Revista de la Sociedad de Estudios Historiológicos y Etnográficos de las Tierras Altas del Argos, Quipar y Alhárabe, 4, pp. 14-19.

Oestigard, T. (2011): "Cosmogony". En Insoll, T. (ed.): The Oxford Handbook of the Archaeology of Ritual and Religion. Oxford: OuP, pp. 76-88.

Olmos, R. (1996): "La representación humana en la cerámica ibérica del Sureste: símbolo y narración". En XXIII Congreso Nacional de Arqueologia (Elche, 1995). Elche: Ayto. de Elche, vol. 1, pp. 275-282.

Olmos, R. (1999): Los iberos y sus imágenes [recurso electrónico-CD]. Madrid: CSIC-Micronet.

Olmos, R. (2008): "La simbolización del espacio sagrado en la antigua Iberia". En Dupré, X.; RIBICHINI, S. y Verger, S.: Saturnia Tellus: definizioni dello spazio consacrato in ambiente etrusco, italico, fenicio-punico, iberico e celtico. Roma: CNRS, pp. 251-265.

Ramallo, S. y Noguera, J. M. (1998): "El Cerro de los Santos y la monumentalización de los santuarios ibéricos tardíos", Revista de Estudios Ibéricos, 3, pp. 11-70.

RowLANDS, M. (1993): "The role of memory in the transmission of culture”, World Archaeology, 25 (2), pp. 141-151.

http://dx.doi.org/10.1080/00438243.1993.9980234 
RuEDA, C. (2011): Territorio, culto e iconografía en los santuarios iberos del Alto Guadalquivir (ss. IV a.n.e.-I d.n.e.). Textos CAAI, 3. Jaén: Univ. de Jaén.

RuIZ, A. (2009): "Del espacio urbano a la ciudad en la sociedad ibera”. En Mateos, P.; Celestino, S.; Pizzo, A. y TortosA, T. (coords.): Santuarios, oppida y ciudades: arquitectura sacra en el desarrollo urbano del Mediterráneo occidental. Anejos de Archivo Español de Arqueología, 45. Madrid: CSIC, pp. 153-174.

Ruiz, A. y Molinos, M. (2002): "El proceso histórico de los Iberos en el Valle Alto del río Guadalquivir". En Molinos, M. y Zifferero, A. (eds.): Primi popoli d'Europa. Firence: All'insegna del Giglio, pp. 291-300.

Ruiz, A. y Molinos, M. (2007): Iberos en Jaén. Jaén: Univ. de Jaén.

Ruiz, A. y Molinos, M. (2008): "Las fuentes del Guadalquivir. Límites y fronteras para el norte de la Bastetania”. En Adroher, A. y BlÁnquez, J. (eds.): Primer Congreso Internacional de Arqueología Ibérica Bastetana. Serie Varia, 9. Madrid, pp. $51-72$.

Ruiz, A.; Molinos, M.; Gutiérrez, L. M. y Bellón, J. P. (2001): "El modelo político del pago en el Alto Guadalquivir (ss. IV-III a.n.e.)”. En MARTín I Ortega, A. y PlanA, R. (coords.): Territori politic $i$ territori rural durant l'Edat del Ferro a la Mediterrània Occidental. Girona: Museu d'Arqueologia de Catalunya, pp. 11-22.
SANZ GAMO, R. (1997): Cultura ibérica y romanización en tierras de Albacete: los siglos de transición. Albacete: Instituto de Estudios Albacetenses.

SCARrE, Ch. (2011): "Monumentality". En Insoll, T. (ed.): The Oxford Handbook of the Archaeology of Ritual and Religion. Oxford: OUP, pp. 9-23.

SCHNAPPS, A. (1997): Le chasseur et la cité. Chasse et érotique dans la Grèce ancienne. Paris: Albin Michel.

Skeates, R.; Gradoli, M. G. y Beckett, J. (2013):

"The Cultural Life of Caves in Seulo, Central Sardinia", Journal of Mediterranean Archaeology, 26 (1), pp. 97-126.

http://dx.doi.org/10.1558/jmea.v26i1.97

http://dx.doi.org/10.1558/jma.v26i1.97

TAÇON, P. (1994): "Socializing landscapes: the longterm implications of signs, symbols and marks on the land", Archaeology of Oceania, 29, pp. 117-129.

Thomas, J. S. (1998): "Some Problems with the Notion of External Symbolic Storage”. En RENFREW, C. y SCARrE, C. (eds.): Cognition and Culture: The Archaeology of External Symbolic Storage. Cambridge: pp. 149-156.

VAn Dommelen, P. (1998): "Punic persistence: colonialism and cultural identity in Roman Sardinia”. En BERRY, J. y LAURENCE, R. (eds.): Cultural identity in the Roman Empire. London: Routledge, pp. 25-48.

WEINER, A. B. (1992): Inalienable possessions: the paradox of keeping-while-giving. Berkeley: University of California Press.

http://dx.doi.org/10.1525/california/9780520076037.001.0001 